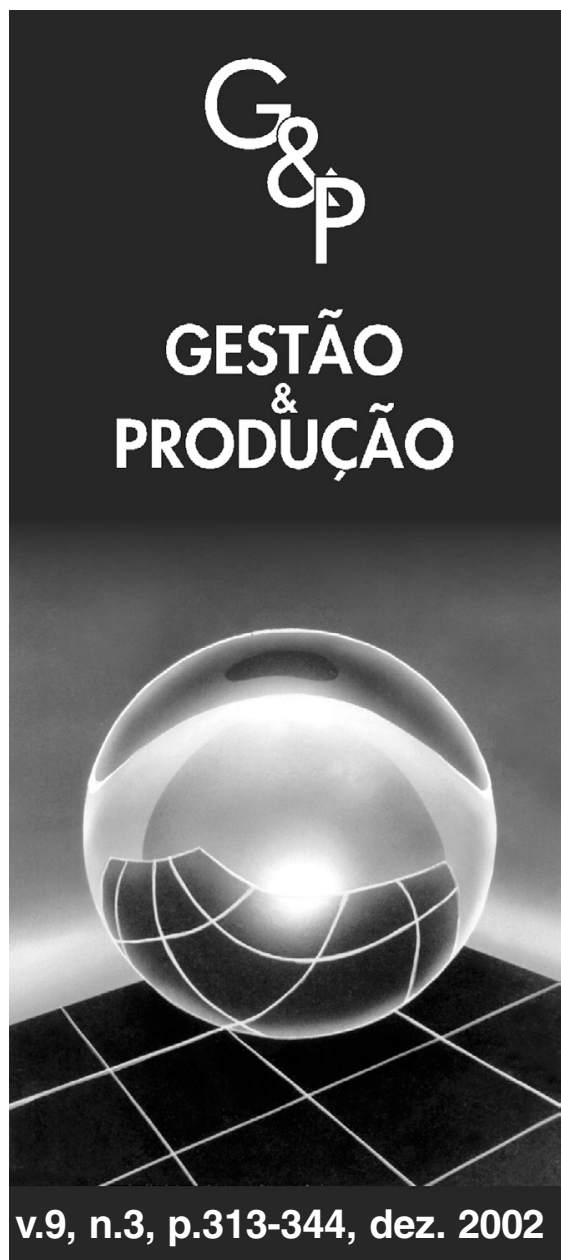

\title{
AUTOMAÇÃO INDUSTRIAL E SISTEMAS INFORMATIZADOS DE GESTÃO DA PRODUÇÃO EM FUNDIÇÕES DE MERCADO
}

\author{
Flavio Cesar F. Fernandes \\ Reinaldo Batista Leite \\ Departamento de Engenharia de Produção, \\ Universidade Federal de São Carlos, \\ Via Washington Luís, km 235, \\ CEP 13565-905, São Carlos, SP, \\ e-mails: dfcf@ power.ufscar.br e \\ reinaldo@polvo.ufscar.br
}

Resumo

Fundição é um processo de fabricação que vem crescendo em importância. O principal objetivo deste artigo é analisar, em termos de automação e sistemas informatizados de gestão da produção (SIGP), as fundições de mercado (fundições que produzem sob encomenda um grande número de pedidos vindos, em geral, de um grande número de clientes) no interior do Estado de São Paulo pertencentes aos 5 principais pólos (Piracicaba, Indaiatuba, Limeira, São Carlos e Itu) com 10 a 250 trabalhadores. Das 61 empresas do interior de São Paulo, 35 situam-se nesses 5 pólos (ou em suas imediações); entrevistamos pessoalmente os diretores industriais e visitamos o chão de fábrica de 30 fundições dentre essas 35. Analisamos quase 200 tabelas de freqüência e de contingência e extraímos várias conclusões, por exemplo: (i) entre os três principais problemas e necessidades relativos à produção, dois deles estão diretamente relacionados com a automação industrial e com os SIGP; (ii) são coincidentes os interesses em automação e SIGP.

Palavras-chave: fundição, produção sob encomenda, automação industrial, sistemas informatizados de gestão da produção. 


\section{Introdução}

A fundição é um processo de fabricação que vem crescendo em importância econômica e tecnológica (Prophet, 1990). Este artigo tem por objetivo principal analisar, em termos de automação e de sistemas informatizados de gestão da produção, as fundições de mercado com 10 a 250 funcionários. Fundições de mercado são aquelas que produzem sob encomenda um grande número de pedidos vindos, em geral, de um grande número de clientes. Algumas das questões aqui focadas são: (i) Até que ponto a automação pode ser importante para o segmento que estamos pesquisando? (ii) Até que ponto processos de decisão mais racionais, baseados em sistemas informatizados de gestão da produção, podem ser importantes para esse segmento?

Além das fundições de mercado, há ainda as fundições cativas que só produzem para a própria empresa (geralmente grandes empresas) ou que são fornecedoras cativas de um ou poucos grandes clientes. As fundições cativas não são objeto de nosso estudo. Havia no interior do Estado de São Paulo 101 fundições (entre cativas e de mercado) catalogadas no Guia ABIFA (Associação Brasileira de Fundição) de fundição 1999 (ABIFA, 1999) e conseguimos identificar 61 fundições de mercado existentes no ano 2000 no interior do Estado. Dessas 61 empresas, 26 pertencem aos 5 principais pólos de fundição de mercado do
Estado de São Paulo (Piracicaba, Indaiatuba, Limeira, São Carlos e Itu) e 9 pertencem à vizinhança desses 5 pólos. Por limitação de tempo e recursos financeiros envolvidos, abordamos pessoalmente (por meio de entrevistas e visitas ao chão de fábrica) 30 dessas 35 empresas. Veja Tabela 1.

Definidas as cidades a serem visitadas, as empresas foram escolhidas aleatoriamente, sem levar em conta os processos, os equipamentos disponíveis ou as ligas dos produtos. As empresas utilizam processos diferentes (algumas utilizam moldagem em areia verde ou areia SHELL, outras utilizam moldagem por processo de cera perdida, por exemplo). Também dispõem de equipamentos diferentes, como na fusão (forno cubilô, forno a óleo, forno a indução) e na moldagem (algumas realizam moldagem manual enquanto outras utilizam máquinas para a moldagem de peças). Algumas possuem gruas para facilitar o transporte de peças maiores e/ou o transporte do metal líquido. Outras possuem equipamentos para a recuperação da areia utilizada no processo. Também há empresas com certificados de qualidade da série ISO 9000. Portanto, a diversidade de materiais, equipamentos e produtos é uma característica marcante do segmento estudado. $\mathrm{O}$ artigo apresenta os resultados de uma pesquisa realizada sobre as condições de automação industrial e sistemas informatizados de gestão da produção em fundições de mercado.

Tabela 1 - Tamanho da amostra (empresas visitadas) e da população por cidade.

\begin{tabular}{lcc|lcc}
\hline Cidade & $\begin{array}{c}\text { Número de } \\
\text { empresas }\end{array}$ & $\begin{array}{c}\text { Empresas } \\
\text { visitadas }\end{array}$ & \multicolumn{1}{c}{ Cidade } & $\begin{array}{c}\text { Número de } \\
\text { empresas }\end{array}$ & $\begin{array}{c}\text { Empresas } \\
\text { visitadas }\end{array}$ \\
\hline Americana & 2 & 1 & Limeira & 5 & 3 \\
Araraquara & 1 & 1 & Monte Alto & 2 & 1 \\
Elias Fausto & 1 & 1 & Piracicaba & 7 & 7 \\
Indaiatuba & 5 & 4 & São Carlos & 5 & 5 \\
Itu & 4 & 4 & Sumaré & 1 & 1 \\
Leme & 2 & 2 & Total global & 35 & 30 \\
\hline
\end{tabular}


As informações aqui contidas poderão subsidiar projetos que visem tornar o segmento mais produtivo, o que, por sua vez, poderá contribuir para a criação de um ambiente de trabalho menos agressivo (péssimas condições de trabalho e baixos salários). Além disso, o estudo apresenta, de forma crítica, diversos indicadores que podem ser utilizados visando a ações estratégicas governamentais e não governamentais para esse setor produtivo.

Dada a finalidade da pesquisa, o método científico utilizado é o método indutivo. No método indutivo não partimos de uma hipótese que pretendemos comprovar, como no caso do método hipotético-dedutivo. Por isso, é na etapa da pesquisa de campo que serão formados os conceitos e hipóteses a serem detalhados.

Quanto aos meios de investigação, Vergara (2000) classifica as pesquisas em pesquisa de campo, pesquisa de laboratório, documental, bibliográfica, experimental, ex post facto, participante, pesquisa-ação ou estudo de caso. Nesse aspecto, os meios de investigação não são mutuamente excludentes. Isso pode ser atribuído a este estudo, que se trata de pesquisa de campo, por ser realizada no local (ou locais) onde ocorre o fenômeno que se deseja estudar. Além disso, envolve o estudo bibliográfico, fornecendo referencial para qualquer outra base de estudo, inclusive à pesquisa de campo.

$\mathrm{Na}$ etapa referente à pesquisa de campo, o procedimento de coleta dos dados escolhido foi a aplicação de um questionário, na forma de entrevista, em que a pessoa da empresa selecionada para o preenchimento do questionário foi alguém com condições de responder às perguntas que extrapolavam o horizonte de planejamento de curto prazo, chegando a um horizonte de planejamento de médio prazo (até três anos).

Por isso, as pessoas selecionadas foram as que ocupam cargo de diretor (preferivelmente o diretor responsável pela área de produção) ou cargo de gerência. O procedimento de coleta dos dados, como descrito anteriormente, se enquadra em pesquisas do tipo survey (pesquisa de avaliação), que consiste em questionários ou entrevistas estruturados com o objetivo de examinar padrões e relacionamentos entre variáveis (Bryman, 1989).

Naturalmente, para subsidiar o projeto também foi feita revisão bibliográfica a respeito de fundições. Encontramos vários problemas, direta ou indiretamente relacionados com este artigo, tratados cada um deles por diversas referências (mas aqui citamos apenas uma para cada um deles), a saber: problemas de flexibilidade do processo produtivo (Mills, 1997); problemas de rapidez de atendimento do cliente (speed) (Drake et al., 1994); sistema de coleta de medidas de acompanhamento do desempenho (Ulusoy et al., 1992); programação da produção para maximizar o volume de produção sujeito a restrições de espaço disponível (Henshell, 1996); sistema de programação da produção visando a melhor utilização dos equipamentos para o aumento da produção (Luther, 1995); qualidade/redução de defeitos (Ransing et al., 1995); implantação do sistema CAD (Courtois et al., 1998); e implantação de equipamentos automatizados controlados por computador (Isermann et al., 1997).

Por outro lado não encontramos (até o ano 2000) referências bibliográficas focando o problema de confiança no cumprimento de prazos de entrega (dependability), sistemas de programação da produção visando a melhor cumprimento de prazos e sistemas de programação da produção visando à redução de consumo de energia. A análise dos resultados foi feita a partir das tabelas de frequiência (tabelas para uma única variável) e das tabelas de contingência (cruzamento de duas variáveis) construídas utilizando o software Excel.

\section{Caracterização do segmento estudado}

Esta seção caracteriza o segmento estudado por meio de quatro subseções: visão geral da indústria de fundição (Seção 2.1), identificação do porte das empresas estudadas e tipos de ligas (Seção 2.2), análise do tamanho médio de lotes e o nível de automação (Seção 2.3) e análise do 
interesse em automação e em sistemas informatizados de gestão (Seção 2.4).

\subsection{Visão geral da indústria de fundição}

No Brasil, a indústria de fundição de peças em ferro, aço e ligas não ferrosas é um segmento da economia que emprega cerca de 38.000 trabalhadores, fatura 2,5 bilhões de dólares por ano e conta com cerca de 1.000 empresas (base 1998). A maioria dessas empresas é de pequeno e médio porte, predominando o capital nacional. Outras características são: o uso intensivo de mão-de-obra e o uso de matérias-primas (ferro gusa, ferroligas, alumínio, etc.) de origem nacional. O Brasil posicionou-se em 1997, segundo a revista Modern Casting de dezembro de 1998, como o $9^{\circ}$ produtor mundial de fundidos. Esta posição pode ser significativamente melhorada.

Há forte tendência de oferecer o produto fundido mais elaborado, ou seja, no mínimo usinado, podendo ser oferecido na forma de um componente ou subconjunto final, montado e até com pintura. Fazem parte desse processo a formação de mão-de-obra mais especializada e o uso de tecnologias mais avançadas.

A base de todos os processos de fundição consiste em alimentar o metal líquido, na cavidade de um molde com o formato requerido, seguindo-se um resfriamento, a fim de produzir um objeto sólido resultante de solidificação (Campos Filho \& Davies, 1978). Os vários processos diferem, principalmente, na maneira de formar o molde. Em alguns casos, como no da moldagem em areia, constrói-se um molde para cada peça a ser fundida, molde este que é rompido para a retirada do fundido, ou seja, para desmoldá-lo. Em outros casos, como, por exemplo, na fundição sob pressão, usa-se um molde permanente, repetidas vezes, para uma sucessão de fundições, removendo-se o fundido após cada fundição, sem danificar o molde. Em ambos os casos, entretanto, é necessária provisão de metal líquido que preencha todas as partes do sistema e permaneça no local até que a solidificação termine.

\subsection{Número de trabalhadores, faturamento e tipos de ligas}

A partir dos dados das tabelas de freqüência (absoluta e/ou relativa), aqui omitidas por limitação de espaço, constatou-se que $90 \%$ são empresas limitadas e $10 \%$ são sociedades anônimas; $96,7 \%$ são de capital nacional; e apenas $6,7 \%$ exportam seus produtos, mas nenhuma das empresas que exportam tem no mercado externo seu principal mercado. $\mathrm{O}$ Quadro 1 apresenta alguns resultados gerais da pesquisa realizada.

Em $100 \%$ das empresas da amostra, a produção é própria, não havendo terceirização de serviços nas atividades de fabricação, exceto na parte de acabamento, em apenas uma empresa, que terceiriza a usinagem de seus produtos. A maioria das empresas do segmento em estudo possui de 10 a 50 trabalhadores (73,34\% das empresas estudadas, Tabela 2). Quanto ao faturamento, 53,33\% das empresas possuem faturamento anual menor que $\mathrm{R} \$ 1$ milhão (Tabela 3).

Tabela 2 - Faixa de número de trabalhadores das empresas.

\begin{tabular}{ccc}
\hline Tamanho & $\begin{array}{c}\text { Faixa de } \mathbf{n}^{\mathbf{0}} \text { total de } \\
\text { trabalhadores }\end{array}$ & \% de empresas \\
\hline 1 & De 10 a 20 & 30,00 \\
2 & De 20 a 50 & 43,34 \\
3 & De 50 a 100 & 13,33 \\
4 & De 100 a 250 & 13,33 \\
\hline
\end{tabular}


Tabela 3 - Faixa de faturamento das empresas.

\begin{tabular}{ccc}
\hline Faturamento & Faixa de faturamento durante 1998 & \% de empresas \\
\hline 1 & Menor que R\$ 1 milhão & 53,33 \\
2 & Entre R\$ 1 e 5 milhões & 36,67 \\
3 & Entre R \$ 5 e 20 milhões & 10,00 \\
\hline
\end{tabular}

\section{Quadro 1 - Alguns resultados das tabelas de freqüiência.}

Da amostra:

- $\quad 90 \%$ das empresas são empresas limitadas e $10 \%$ são sociedades anônimas.

- $\quad 96,7 \%$ das empresas são de capital nacional.

- $\quad 6,7 \%$ das empresas exportam seus produtos.

- $100 \%$ das empresas possuem produção própria.

- $\quad 73,3 \%$ das empresas tinham interesse em automação industrial.

- $\quad 80 \%$ das empresas tinham interesse em sistemas informatizados para gestão da produção.

- Fatores limitantes para que haja investimentos em automação industrial/sistemas informatizados para gestão da produção (foi possível assinalar até 3 fatores):

○ $76,7 \%$ das empresas assinalaram a disponibilidade de recursos financeiros;

○ $43,3 \%$ assinalaram a perspectiva de crescimento da economia;

- $46,7 \%$ assinalaram o volume de produção;

- $23,3 \%$ assinalaram o nível tecnológico do mercado concorrencial;

- $23,3 \%$ assinalaram a qualidade da mão-de-obra;

○ $10 \%$ assinalaram a necessidade de mais informações sobre automação industrial; e

- $10 \%$ assinalaram a necessidade de mais informações sobre sistemas informatizados de gestão da produção.

Fusão em ferro representa 39,22\% das linhas fundidas, enquanto o aço representa $25,49 \%$, o alumínio, $13,73 \%$ e o aço inox, $11,76 \%$ (Tabela 4). Cabe aqui ressaltar que muitas empresas possuem apenas uma linha de produtos $(50 \%$ das empresas estudadas), enquanto outras possuem as linhas A e B (30\%) ou linhas A, B e C (20\% das empresas estudadas).

Para as cidades de Indaiatuba, Itu, Piracicaba e São Carlos, que são aquelas com o maior número de empresas visitadas, construímos um gráfico com o porcentual do faturamento correspondente a cada uma das ligas (cada empresa apontava o porcentual da produção que era correspondente a cada uma das linhas de produtos). Isso é mostrado nas Figuras 1 a 4 . A predominância das ligas de ferro ficou bem evidente nas cidades de Itu (Figura 2) e de Piracicaba (Figura 3), mas uma participação considerável dessa liga também é verificada nas 
cidades de Indaiatuba e São Carlos (Figuras 1 e 4, respectivamente). Em segundo lugar em participação aparecem as ligas de aço e em terceiro lugar, as ligas de alumínio. A exceção ocorre na cidade de Itu, onde as ligas de ferro têm maior participação, seguidas por ligas de alumínio. Somente uma empresa produz aços especiais e ela se encontra na cidade de São Carlos. Vale destacar que maior conhecimento técnico é necessário para produzir fundidos de ligas de aço, em particular para produzir ligas de aço especiais.

Há relação entre o número de trabalhadores na produção e o tipo de liga (Tabela 5): das indústrias com até 20 trabalhadores na produção, $78 \%$ produzem as ligas 1 (ferro) e 2 (alumínio); das com 20 a 50 trabalhadores, para a amostra, nenhuma produz a liga 6 (aço especial) e $69 \%$ produzem as ligas 1 (ferro) e 4 (aço); e as indústrias com mais de 50 trabalhadores, para a amostra, não produzem as ligas 3 (cobre) e 7 (cobalto) e $64 \%$ delas produzem as ligas 1 (ferro) e 4 (aço).

As ligas 6 (aço especial) e 7 (cobalto) são utilizadas, na amostra, em apenas uma empresa para cada liga, sendo uma com mais de 100 trabalhadores (no caso da liga 6) e uma entre 20 e 50 trabalhadores (no caso da liga 7).

Com relação às ligas, faturamento $\mathrm{e}$ mercados [nacional e regional (raio de $100 \mathrm{~km}$ )], observamos que $100 \%$ das linhas de produtos que apresentam o maior faturamento anual (entre R\$ 5 e 20 milhões) têm o mercado nacional como principal mercado (Tabela 6). O mercado nacional também é predominante na maioria das linhas de produtos que trabalha com ligas de cobalto, aço, aço inox e aço especial $(100 \%, 69,2 \%, 66,7 \%$ e $100 \%$, respectivamente, têm o mercado nacional como principal mercado - Tabela 7). Isso pode ser justificado pela maior complexidade dos processos utilizados na fabricação de produtos a partir dessas ligas, o que deve restringir o mercado a empresas que estejam mais preparadas para produzir os produtos respeitando os níveis de qualidade exigidos. Tais exigências são menores nos processos de fabricação utilizando ligas de ferro, cobre e alumínio.

Os clientes das fundições com faturamento mais alto (entre R\$ 5 e 20 milhões) são dos ramos automobilístico e metal-mecânico; as de faturamento médio (entre $\mathrm{R} \$ 1$ e 5 milhões) atendem a clientes dos ramos automobilístico, metal-mecânico e químico; as de baixo faturamento atendem a clientes dos ramos (em ordem de importância): metal-mecânico, automobilístico, químico, alimentos e construção civil (Tabela 8).

Além disso, apenas o ramo químico demanda aço especial; o de alimentos demanda ligas de alumínio e aço inox; o metal-mecânico só não utiliza os aços especiais; e a indústria automobilística demanda (em ordem de importância) ferro fundido, aço fundido e alumínio fundido (Tabela 9).

Tabela 4 - Linha de produtos.

\begin{tabular}{ccc}
\hline Liga & Linha de produtos & \% das linhas de produtos \\
\hline 1 & Ligas de ferro & 39,22 \\
2 & Ligas de alumínio & 13,73 \\
3 & Ligas de cobre & 5,88 \\
4 & Aço & 25,49 \\
5 & Aço inox & 11,76 \\
6 & Aço especial & 1,96 \\
7 & Ligas de cobalto & 1,96 \\
\hline
\end{tabular}




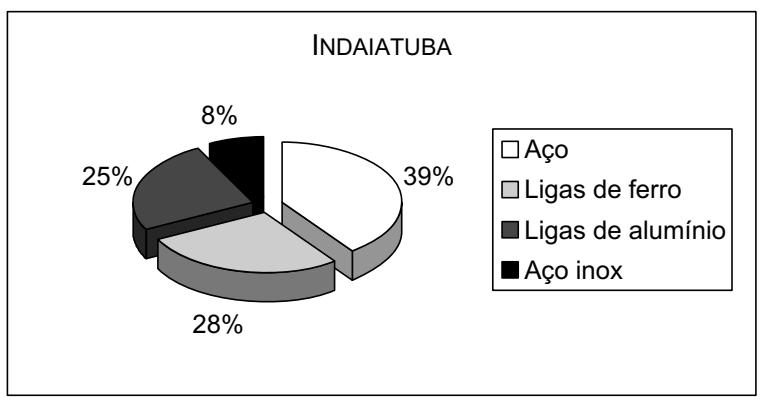

Figura 1 - Porcentual do faturamento por liga em Indaiatuba.

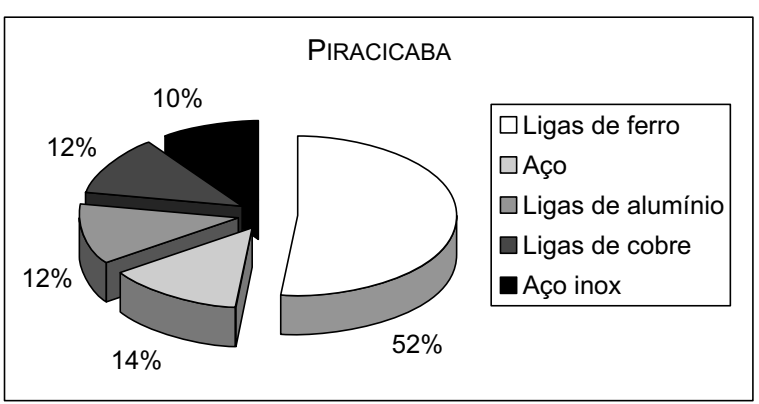

Figura 3 - Porcentual do faturamento por liga em Piracicaba.

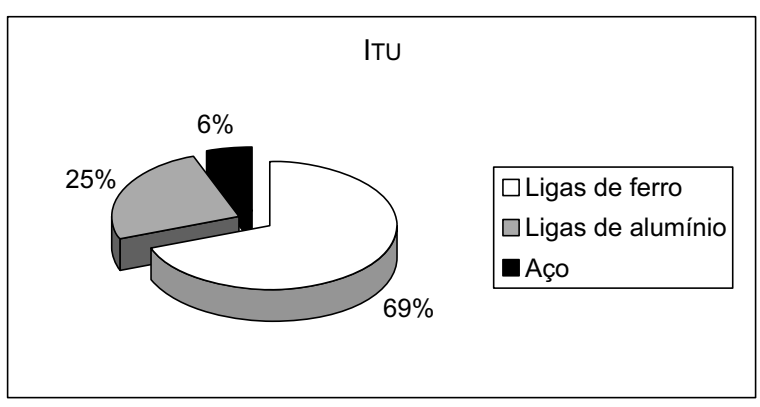

Figura 2 - Porcentual do faturamento por liga em Itu.

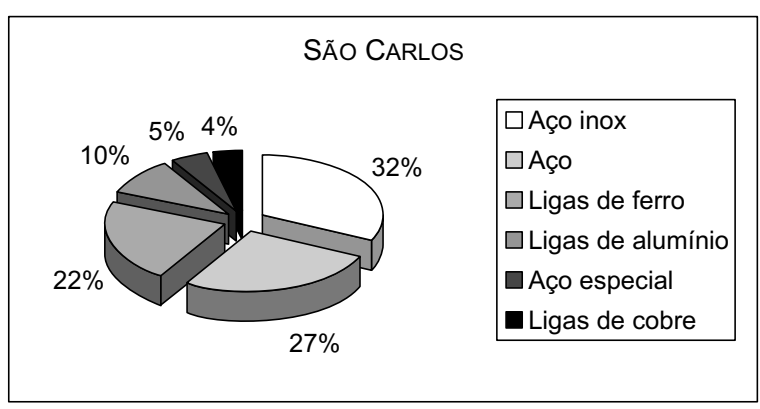

Figura 4 - Porcentual do faturamento por liga em São Carlos.

Tabela 5 - Número de linhas de produtos do cruzamento total de trabalhadores na produção versus liga.

\begin{tabular}{lccccccc}
\hline $\begin{array}{c}\text { Total de } \\
\text { trabalhadores } \\
\text { na produção }\end{array}$ & $\begin{array}{c}\text { Ligas de } \\
\text { Fe (1) }\end{array}$ & $\begin{array}{c}\text { Ligas de } \\
\text { Al (2) }\end{array}$ & $\begin{array}{c}\text { Ligas de } \\
\text { Cu (3) }\end{array}$ & $\begin{array}{c}\text { Aço } \\
\text { carbono (4) }\end{array}$ & $\begin{array}{c}\text { Aço } \\
\text { inox (5) }\end{array}$ & $\begin{array}{c}\text { Aço } \\
\text { especial (6) }\end{array}$ & $\begin{array}{c}\text { Ligas de } \\
\text { Co (7) }\end{array}$ \\
\hline Menos de 20 & 7 & 4 & 2 & 1 & 0 & 0 & 0 \\
De 20 a 50 & 10 & 2 & 1 & 8 & 4 & 0 & 1 \\
De 50 a 100 & 2 & 1 & 0 & 2 & 1 & 0 & 0 \\
De 100 a 250 & 1 & 0 & 0 & 2 & 1 & 1 & 0 \\
\hline
\end{tabular}

Tabela 6 - Número de linhas de produtos do cruzamento faturamento versus principal mercado.

\begin{tabular}{lccc}
\hline \multirow{2}{*}{ Faturamento da linha } & \multicolumn{2}{c}{ Principal mercado } & \multirow{2}{*}{$\begin{array}{c}\text { Total por faixa de } \\
\text { faturamento }\end{array}$} \\
\cline { 2 - 3 } & Regional (raio de 100 km) & Nacional & 18 \\
\hline Menor que R\$ 1 milhão & 15 & 9 & 33 \\
Entre R\$ 1 e 5 milhões & 6 & 3 & 15 \\
Entre R\$ 5 e 20 milhões & 0 & 30 & 51 \\
Total por tipo de liga & 21 & & 3 \\
\hline
\end{tabular}


Tabela 7 - Número de linhas de produtos do cruzamento total do principal mercado versus liga.

\begin{tabular}{lcccccccc}
\hline \multirow{2}{*}{$\begin{array}{c}\text { Principal } \\
\text { mercado }\end{array}$} & $\begin{array}{c}\text { Ligas de } \\
\text { Fe (1) }\end{array}$ & $\begin{array}{c}\text { Ligas de } \\
\text { Al (2) }\end{array}$ & $\begin{array}{c}\text { Ligas de } \\
\text { Cu (3) }\end{array}$ & $\begin{array}{c}\text { Aço } \\
\text { carbono (4) }\end{array}$ & $\begin{array}{c}\text { Aço } \\
\text { inox (5) }\end{array}$ & $\begin{array}{c}\text { Aço } \\
\text { especial (6) }\end{array}$ & $\begin{array}{c}\text { Ligas de } \\
\text { Co (7) }\end{array}$ & $\begin{array}{c}\text { Total por } \\
\text { mercado }\end{array}$ \\
\hline $\begin{array}{l}\text { Regional } \\
\text { (raio de } 100 \mathrm{~km})\end{array}$ & 9 & 4 & 2 & 4 & 2 & 0 & 0 & 21 \\
Nacional & 11 & 3 & 1 & 9 & 4 & 1 & 1 & 30 \\
Total por tipo de liga & 20 & 7 & 3 & 13 & 6 & 1 & 1 & 51 \\
\hline
\end{tabular}

Tabela 8 - Número de linhas de produtos do cruzamento faturamento versus ramo de atividade dos clientes.

\begin{tabular}{lccccc}
\hline \multirow{2}{*}{ Faturamento da linha } & \multicolumn{5}{c}{ Principal ramo de atividade dos clientes } \\
\cline { 2 - 6 } & Automobilístico & $\begin{array}{c}\text { Indústria } \\
\text { química }\end{array}$ & Alimentos & $\begin{array}{c}\text { Metal- } \\
\text { mecânica }\end{array}$ & Construção civil \\
\hline Menor que R\$ 1 milhão & 5 & 2 & 2 & 23 & 1 \\
Entre R \$ 1 e 5 milhões & 6 & 3 & 0 & 6 & 0 \\
Entre R \$ 5 e 20 milhões & 2 & 0 & 0 & 1 & 0 \\
\hline
\end{tabular}

Tabela 9 - Número de linhas de produtos do cruzamento ramo de atividade dos clientes versus liga.

\begin{tabular}{lccccccc}
\hline \multirow{2}{*}{$\begin{array}{c}\text { Principal ramo de } \\
\text { atividade dos clientes }\end{array}$} & $\begin{array}{c}\text { Ligas de } \\
\text { Fe (1) }\end{array}$ & $\begin{array}{c}\text { Ligas de } \\
\text { Al (2) }\end{array}$ & $\begin{array}{c}\text { Ligas de } \\
\text { Cu (3) }\end{array}$ & $\begin{array}{c}\text { Aço } \\
\text { carbono (4) }\end{array}$ & $\begin{array}{c}\text { Aço } \\
\text { inox (5) }\end{array}$ & $\begin{array}{c}\text { Aço } \\
\text { especial (6) }\end{array}$ & $\begin{array}{c}\text { Ligas de } \\
\text { Co (7) }\end{array}$ \\
\hline Automobilístico & 7 & 2 & 0 & 4 & 0 & 0 & 0 \\
Indústria química & 1 & 0 & 0 & 1 & 2 & 1 & 0 \\
Alimentos & 0 & 1 & 0 & 0 & 1 & 0 & 0 \\
Metal-mecânica & 11 & 3 & 3 & 8 & 3 & 0 & 1 \\
Construção civil & 1 & 1 & 0 & 0 & 0 & 0 & 0 \\
\hline
\end{tabular}

\subsection{Tamanho médio de lotes e nível de automação}

Foi constatado (Tabela 10) que a maioria das linhas de produtos trabalha em média com lotes pequenos, de 2 a 100 peças $(68,33 \%$ das linhas). Isso é decorrência do segmento estudado, ou seja, fundições de mercado, que trabalham por encomenda, aliado à confirmação da seguinte premissa: possuem grande diversidade de produtos e trabalham com diversos clientes.

A surpresa na Tabela 10 é que apenas 5,88\% das linhas de produtos são produzidas em lotes unitários; esperávamos uma porcentagem significativamente maior. 
Tabela 10 - Tamanho médio de lote das empresas.

\begin{tabular}{ccc}
\hline Tamanho & Faixa de tamanho médio de lote & \% das linhas de produtos \\
\hline 1 & Unitário & 5,88 \\
2 & De 2 a 100 & 68,33 \\
3 & De 101 a 1000 & 21,57 \\
4 & Acima de 1000 & 03,92 \\
\hline
\end{tabular}

Independentemente do número de trabalhadores, a predominância é dos lotes pequenos (Tabela 11). Das empresas com menos de 20 trabalhadores, $78 \%$ trabalham com lotes pequenos; para as empresas entre 20 e 50 trabalhadores, esse valor passa para $69 \%$, mudando para $50 \%$ e $60 \%$ para as empresas entre 50 e 100 trabalhadores e para as empresas com mais de 100 trabalhadores, respectivamente. Os dois casos de lotes grandes correspondem a empresas com menos de 20 trabalhadores; na realidade, são empresas que, embora produzam sob encomenda, produzem para poucos clientes e praticamente são cativas desses clientes.

Independentemente do tipo de liga, inclusive para o alumínio, que apresenta um caso de lote unitário e um de lote grande, além de cinco com lotes pequenos, a moda estatística é lote pequeno (Tabela 12). A única exceção ocorre com ligas de cobalto, que na amostra aparece em apenas uma linha de produtos, que opera com lotes médios. Todos os casos das ligas de cobre e aço especial acontecem com lotes pequenos. Não há nenhum caso de lote grande para o ferro fundido nem de lote unitário para o aço.

O nível de automação encontrado nas empresas de fundição de mercado dos 5 pólos estudados é bastante baixo. O que há de mais automatizado nas empresas é a presença de equipamentos mecânicos para a moldagem, porém nem todos os produtos podem ser moldados nesses equipamentos. Outros equipamentos automatizados encontrados não são implantados com o objetivo de reduzir o número de trabalhadores. Sistemas para a recuperação da areia de fundição são exemplos típicos em que o objetivo não é a redução do número de trabalhadores na produção, mas, antes, preocupação ambiental [depois de utilizada em moldes na indústria de fundição, a areia fica contaminada por metais pesados, principalmente cobre e chumbo, e por fenóis originados das resinas empregadas na sua compactação (San Martin \& Campanili, 2002)] ou mesmo preocupação em reduzir os custos com a redução das compras de areia para fundição. Tabela 11 - Número de linhas de produtos do cruzamento tamanho
médio de lote versus total de trabalhadores na produção.

\begin{tabular}{lcccc}
\hline \multicolumn{1}{c}{ Faixa de tamanho } & \multicolumn{4}{c}{ Faixa de total de trabalhadores na produção } \\
\cline { 2 - 5 } \multicolumn{1}{c}{ médio de lote } & Menos de 20 & De 20 a 50 & De 50 a 100 & De 100 a 250 \\
\hline Unitário & 0 & 1 & 2 & 0 \\
Pequeno (de 2 a 100) & 11 & 18 & 3 & 3 \\
Médio (de 101 a 1000) & 1 & 7 & 1 & 2 \\
Grande (acima de 1000) & 2 & 0 & 0 & 0 \\
\hline
\end{tabular}


Tabela 12 - Número de linhas de produtos do cruzamento tamanho médio de lote da linha versus liga.

\begin{tabular}{lccccccc}
\hline \multirow{2}{*}{$\begin{array}{c}\text { Faixa de tamanho } \\
\text { médio de lote }\end{array}$} & $\begin{array}{c}\text { Ligas de } \\
\text { Fe (1) }\end{array}$ & $\begin{array}{c}\text { Ligas de } \\
\text { Al (2) }\end{array}$ & $\begin{array}{c}\text { Ligas de } \\
\text { Cu (3) }\end{array}$ & $\begin{array}{c}\text { Aço } \\
\text { carbono (4) }\end{array}$ & $\begin{array}{c}\text { Aço } \\
\text { inox (5) }\end{array}$ & $\begin{array}{c}\text { Aço } \\
\text { especial (6) }\end{array}$ & $\begin{array}{c}\text { Ligas de } \\
\text { Co (7) }\end{array}$ \\
\hline Unitário & 2 & 1 & 0 & 0 & 0 & 0 & 0 \\
Pequeno (de 2 a 100) & 14 & 5 & 3 & 8 & 4 & 1 & 0 \\
Médio (de 101 a 1000) & 4 & 0 & 0 & 4 & 2 & 0 & 1 \\
Grande (acima de 1000) & 0 & 1 & 0 & 1 & 0 & 0 & 0 \\
\hline
\end{tabular}

Alguns dos equipamentos utilizados nas 4 empresas com menor razão entre faturamento anual (valor médio da faixa de faturamento, visto que muitas empresas se recusam a fornecer os valores precisos de faturamento) e total de trabalhadores na produção são mostrados na Tabela 13 e alguns equipamentos utilizados nas 4 empresas com maior razão entre faturamento anual e total de trabalhadores na produção são mostrados na Tabela 14 .

Analisando as Tabelas 13 e 14, notamos que as empresas E27 e E01 possuem forno de indução e misturador de areia convencional (mecânico) e não possuem sistema $\mathrm{CAD}$. As diferenças se devem ao fato de que a E27 não tem recuperação de areia e a E01 possui. Mas isso não explica a grande diferença de faturamento/trabalhador. $\mathrm{O}$ que difere e explica a diferença é o know-how da E01 em operar com materiais mais caros e que demandam alta tecnologia. Ou seja, o faturamento/trabalhador é muito mais função da tecnologia do produto (no caso da fundição corresponde ao know-how requerido para operar com determinados aços especiais) do que da tecnologia do processo de fabricação.

As empresas com alto faturamento/trabalhador em geral possuem mais recursos financeiros e investem em sistema para recuperação de areia. $\mathrm{O}$ comportamento das faixas de faturamento (faixas 1, 2 e 3) relacionadas com o número de trabalhadores está apresentado na Figura 5.

Em geral, quanto maior o faturamento, maior o número de trabalhadores, mas há algumas exceções.

Uma empresa (trabalhando com ligas de ferro) com mais de 40 funcionários pertence à faixa de faturamento 1; duas empresas (uma delas trabalhando com ligas de alumínio e a outra, com ligas de aço inox e aço carbono) com menos de 40 trabalhadores apresentam faturamento na faixa 2; e uma empresa (trabalhando com ligas de ferro, aço carbono e alumínio) com menos de 100 trabalhadores apresenta faturamento na faixa 3 . Novamente, essas exceções são explicadas mais pela tecnologia dos materiais envolvidos na fundição do que pelas diferenças na tecnologia dos processos de fabricação.

$\mathrm{Na}$ grande maioria das empresas com lotes pequenos, os clientes pertencem ao ramo metalmecânico (68,6\%, Tabela 15), já as empresas com lotes médios estão concentradas nos ramos metal-mecânico $(45,4 \%)$ e automobilístico $(27,2 \%)$. Vale a pena ressaltar ainda: os ramos metal-mecânico e automobilístico são os ramos predominantes e, para o ramo da indústria química, $80 \%$ dos lotes são pequenos. 
Tabela 13 - Alguns equipamentos presentes nas empresas com menor razão faturamento/trabalhadores.

\begin{tabular}{|c|c|c|c|c|}
\hline Empresa & $\begin{array}{c}\text { Faturamento } \\
\text { anual (1999) }\end{array}$ & $\begin{array}{l}\text { Trabalhadores } \\
\text { na produção }\end{array}$ & Fat./trab. & Equipamentos \\
\hline \multirow[t]{2}{*}{ E27 } & \multirow[t]{2}{*}{$\mathrm{R} \$ 500.000,00$} & \multirow[t]{2}{*}{25} & \multirow[t]{2}{*}{$\mathrm{R} \$ 20.000,00$} & $\begin{array}{l}\text { Forno a indução; misturador de areia } \\
\text { convencional (mecânico) }\end{array}$ \\
\hline & & & & Sem recuperação de areia; sem sistema CAD \\
\hline \multirow{2}{*}{ E28 } & \multirow{2}{*}{$\mathrm{R} \$ 500.000,00$} & \multirow{2}{*}{33} & \multirow{2}{*}{$\mathrm{R} \$ 15.151,52$} & $\begin{array}{l}\text { Forno a óleo e cubilô; máquinas para a } \\
\text { moldagem }\end{array}$ \\
\hline & & & & $\begin{array}{l}\text { Sem sistema CAD; sem sistema para a } \\
\text { recuperação de areia }\end{array}$ \\
\hline \multirow[t]{2}{*}{ E29 } & \multirow[t]{2}{*}{$\mathrm{R} \$ 500.000,00$} & \multirow[t]{2}{*}{34} & \multirow[t]{2}{*}{$\mathrm{R} \$ 14.705,88$} & $\begin{array}{l}\text { Forno cubilô (indução em instalação); sistema } \\
\text { para a recuperação de areia }\end{array}$ \\
\hline & & & & Sem sistema CAD \\
\hline \multirow[b]{2}{*}{ E30 } & \multirow[b]{2}{*}{$\mathrm{R} \$ 500.000,00$} & \multirow[b]{2}{*}{38} & \multirow[b]{2}{*}{$\mathrm{R} \$ 13.157,89$} & Forno a indução; máquinas para a moldagem \\
\hline & & & & $\begin{array}{l}\text { Sem sistema CAD; sem sistema para a } \\
\text { recuperação de areia }\end{array}$ \\
\hline
\end{tabular}

Tabela 14 - Alguns equipamentos presentes nas empresas com maior razão faturamento/trabalhadores.

\begin{tabular}{|c|c|c|c|c|}
\hline Empresa & $\begin{array}{l}\text { Faturamento } \\
\text { anual (1999) }\end{array}$ & $\begin{array}{l}\text { Trabalhadores } \\
\text { na produção }\end{array}$ & Fat./trab. & Equipamentos \\
\hline \multirow[t]{2}{*}{ E01 } & \multirow[t]{2}{*}{$\mathrm{R} \$ 15.000 .000,00$} & \multirow[t]{2}{*}{52} & \multirow[t]{2}{*}{$\mathrm{R} \$ 288.461,54$} & $\begin{array}{l}\text { Forno a indução; misturador de areia } \\
\text { convencional (mecânico); sistema para a } \\
\text { recuperação de areia }\end{array}$ \\
\hline & & & & Sem sistema CAD \\
\hline \multirow[t]{2}{*}{ E02 } & \multirow[t]{2}{*}{$\mathrm{R} \$ 3.500 .000,00$} & \multirow[t]{2}{*}{23} & \multirow[t]{2}{*}{$\mathrm{R} \$ 152.173,91$} & $\begin{array}{l}\text { Forno a indução; misturador de areia } \\
\text { convencional (mecânico); sistema CAD (faz } \\
\text { pouca modelagem) }\end{array}$ \\
\hline & & & & Sem sistema para a recuperação de areia \\
\hline E03 & $\mathrm{R} \$ 15.000 .000,00$ & 110 & $\mathrm{R} \$ 136.363,64$ & $\begin{array}{l}\text { Forno a indução de alta freqüência; } \\
\text { misturador de areia convencional } \\
\text { (mecânico); sistema para a recuperação de } \\
\text { areia; sistema CAD (não usado para } \\
\text { modelagem) }\end{array}$ \\
\hline E04 & $\mathrm{R} \$ 3.500 .000,00$ & 30 & $\mathrm{R} \$ 116.666,67$ & $\begin{array}{l}\text { Forno a gás; máquinas para a moldagem; } \\
\text { sistema para recuperação de areia } \\
\text { Sem sistema CAD }\end{array}$ \\
\hline
\end{tabular}




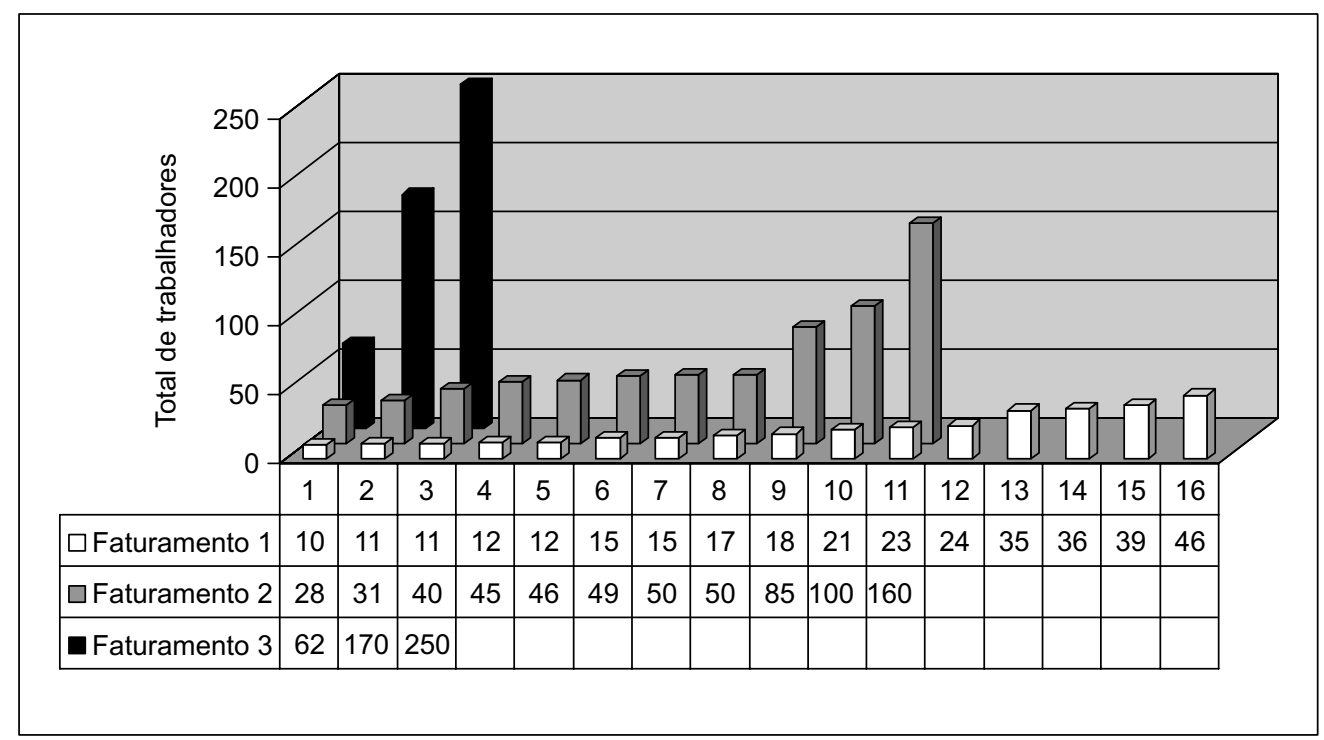

Figura 5 - Total de trabalhadores por faixa de faturamento.

Tabela 15 - Principal ramo de atividade dos clientes versus tamanho médio de lote.

\begin{tabular}{lccccc}
\hline & \multicolumn{5}{c}{ Principal ramo dos clientes } \\
\cline { 2 - 6 } Tamanho médio de lote & Automobilístico & $\begin{array}{c}\text { Indústria } \\
\text { química }\end{array}$ & Alimentos & $\begin{array}{c}\text { Metal- } \\
\text { mecânica }\end{array}$ & $\begin{array}{c}\text { Construção } \\
\text { civil }\end{array}$ \\
\hline Unitário & 3 & 0 & 0 & 0 & 0 \\
Pequeno (de 2 a 100) & 7 & 4 & 0 & 24 & 0 \\
Médio (de 101 a 1000) & 3 & 1 & 1 & 5 & 1 \\
Grande (acima de 1000) & 0 & 0 & 1 & 1 & 0 \\
\hline
\end{tabular}

\subsection{Interesse em automação e em sistemas informatizados de gestão}

Das empresas pertencentes à amostra, 73,3\% apresentaram interesse em automação industrial e $80 \%$ apresentaram interesse em sistemas informatizados para gestão da produção (ver Quadro 1).

Quanto à automação/informatização, as empresas têm interesse, mas há empecilhos. Dos fatores mais importantes para que haja investimentos em automação industrial e em sistemas informatizados de gestão da produção, $76,7 \%$ das empresas assinalaram a disponibi- lidade de recursos financeiros; $43,3 \%$ assinalaram a perspectiva de crescimento da economia; $46,7 \%$, o volume de produção; $23,3 \%$, o nível tecnológico do mercado concorrencial; 23,3\%, a qualidade da mão-de-obra; $10 \%$, a necessidade de mais informações sobre automação industrial; e $10 \%$, a necessidade de mais informações sobre sistemas informatizados de gestão da produção (ver Quadro 1). É importante ressaltar que cada empresa destacava dentre as opções as três consideradas mais importantes.

O interesse em automação/sistemas informatizados de gestão é alto, porém, a automatização atual é baixa. O que se tem de mais automa- 
tizado em muitas delas são fornos que controlam com maior rigor a temperatura do metal. Em um número menor de empresas pudemos encontrar máquinas para fabricação de moldes (com alimentação automática ou não) e sistemas para a recuperação da areia de fundição.

Verificamos que tanto para as empresas com faturamento pequeno quanto para as empresas de faturamento médio o interesse em automação é bastante elevado $(75 \%$ e $82 \%$, respectivamente - Tabela 16), enquanto para as empresas de faturamento grande esse percentual de interesse cai para $33 \%$.

Pela Tabela 17 observa-se que empresas com baixo ou médio nível de automação apresentam grande interesse em automação (80\% e $77 \%$, respectivamente). Por outro lado, somente $33 \%$ das empresas com alto nível de automação apresentam interesse em automação.

Nossa atenção foi despertada para o fato de uma alta porcentagem de empresas que produzem em pequenos lotes apresentarem interesse em automação (Tabela 18). Porém, esse interesse é limitado a certos aspectos específicos do processo, por exemplo, forno com controles mais automatizados, melhor controle da temperatura ou, ainda, aparelhos mais automatizados para seus laboratórios de análise.

As empresas que consideram o mercado pouco concorrido apresentaram menos interesse em automação do que empresas que consideram o mercado muito concorrido $(20 \%$ e $84 \%$, respectivamente - Tabela 19).

Embora a Tabela 40 mostre que o projeto de implantação de equipamentos automatizados tenha importância consideravelmente alta para as empresas que se consideram em um mercado pouco concorrido, se comparada com as demais empresas (mercado muito concorrido), a situação de pouca concorrência não estimula essas empresas a investir (ou a ter interesse em investir) em equipamentos automatizados (Tabela 19). Em empresas cujos principais clientes são dos ramos automobilístico e metal-mecânico, o interesse em automação é bastante elevado $(67 \%$ e $81 \%$, respectivamente - Tabela 20).

Tabela 16 - Interesse em automação versus faixa de faturamento anual.

\begin{tabular}{lcccc}
\hline \multirow{2}{*}{$\begin{array}{c}\text { Interesse em } \\
\text { automação }\end{array}$} & \multicolumn{3}{c}{ Faixa de faturamento anual } & Total por \\
\cline { 2 - 5 } & Até R\$ 1 milhão & Entre R\$ 1 e 5 milhões & Entre R\$ 5 e 20 milhões & interesse \\
\hline Não & 4 & 2 & 2 & 8 \\
Sim & 12 & 9 & 1 & 22 \\
Total por faturamento & 16 & 11 & 3 & 30 \\
\hline
\end{tabular}

Tabela 17 - Interesse em automação versus nível de automação.

\begin{tabular}{lcccc}
\hline \multirow{2}{*}{ Interesse em automação } & \multicolumn{3}{c}{ Nível de automação } & \multirow{2}{*}{$\begin{array}{c}\text { Total por } \\
\text { interesse }\end{array}$} \\
\cline { 2 - 4 } & Baixo & Intermediário & Alto & \\
\hline Não & 1 & 5 & 2 & 8 \\
Sim & 4 & 17 & 1 & 22 \\
Total por nível de automação & 5 & 22 & 3 & 30 \\
\hline
\end{tabular}


Tabela 18 - Interesse em automação versus tamanho médio de lote.

\begin{tabular}{lcccccc}
\hline \multirow{2}{*}{ Interesse em automação } & \multicolumn{4}{c}{ Faixa de tamanho médio de lote } & Total por \\
\cline { 2 - 5 } & Unitário & Pequeno & Médio & Grande & interesse \\
\hline Não & 1 & 4 & 3 & 0 & 8 \\
Sim & 1 & 17 & 3 & 1 & 22 \\
Total por tamanho de lote & 2 & 21 & 6 & 1 & 30 \\
\hline
\end{tabular}

Tabela 19 - Interesse em automação versus nível de concorrência.

\begin{tabular}{|c|c|c|c|}
\hline \multirow{2}{*}{ Interesse em automação } & \multicolumn{2}{|c|}{ Nível de concorrência } & \multirow{2}{*}{$\begin{array}{l}\text { Total por } \\
\text { interesse }\end{array}$} \\
\hline & Pouca concorrência & Muita concorrência & \\
\hline Não & 4 & 4 & 8 \\
\hline Sim & 1 & 21 & 22 \\
\hline Total por concorrência & 5 & 25 & 30 \\
\hline
\end{tabular}

A maioria das fundições aponta que seus principais clientes pertencem a esses dois ramos. Para o ramo automobilístico, as quantidades de produtos envolvidos é bastante alta, o que viabiliza a automação dos processos produtivos, por isso possivelmente essas empresas declararam interesse em automação. A justificativa para o grande interesse em automação pode estar no nível elevado de concorrência apontado por $87 \%$ das empresas entrevistadas cujo principal ramo de atividade dos clientes é o metal-mecânico. Porém, como grande parte (80\%) das empresas cujo principal ramo dos clientes é o metal-mecânico trabalha em média com lotes pequenos, a automatização de partes do processo pode ser melhor para elas (como aquisição de fornos mais automatizados ou equipamentos que automatizem moldagem, por exemplo).

Empresas cujos negócios estão em declínio não demonstram interesse em automação (Tabela 21). Tanto para empresas estáveis como para empresas em crescimento há grande porcentual de interesse em automação (77\% e $78 \%$, respectivamente). Essas empresas desejam aumentar sua competitividade por meio da automação e por isso apontaram interesse nela.

Para as empresas com faturamento anual de até R\$ 5 milhões, o interesse em sistema informatizado de gestão apresenta proporção muito alta (85\% - Tabela 22). Apenas para empresas com faturamento anual acima de $\mathrm{R} \$ 5$ milhões o interesse em sistema informatizado de gestão não apresentou proporção elevada (33\%). Isso se deve ao fato de que empresas com esse faturamento (acima de R $\$ 5$ milhões anuais) já possuem tais sistemas. Todas as 3 empresas com faturamento acima de $\mathrm{R} \$ 5$ milhões possuem versão informatizada implantada para emissão de ordens de compras, emissão de ordens de produção e codificação de materiais. Já a programação fina da produção é informatizada em apenas uma delas.

Para todos os níveis de automação (desde baixo até alto) há um porcentual elevado de interesse em sistema informatizado de gestão (Tabela 23), o que reflete a importância dada pelas empresas a esse tipo de sistema de gestão, que agiliza a troca de informações na empresa, facilitando e acelerando seu gerenciamento. 
Tabela 20 - Interesse em automação versus principal ramo dos clientes.

\begin{tabular}{lccccc}
\hline \multirow{2}{*}{$\begin{array}{c}\text { Interesse em } \\
\text { automação }\end{array}$} & \multicolumn{5}{c}{ Principal ramo de atividade dos clientes } \\
\cline { 2 - 6 } & Automobilístico & Indústria química & Alimentos & Metal-mecânica & Construção civil \\
\hline Não & 3 & 1 & 1 & 3 & 0 \\
Sim & 6 & 1 & 1 & 13 & 1 \\
\hline
\end{tabular}

Tabela 21 - Interesse em automação versus tendência dos negócios da empresa.

\begin{tabular}{lcccc}
\hline \multirow{2}{*}{$\begin{array}{c}\text { Interesse em } \\
\text { automação }\end{array}$} & \multicolumn{4}{c}{ Tendência dos negócios da empresa } \\
\cline { 2 - 5 } & Crescimento rápido & Em crescimento & Estável & Em declínio \\
\hline Não & 1 & 3 & 3 & 1 \\
Sim & 1 & 11 & 10 & 0 \\
\hline
\end{tabular}

Tabela 22 - Interesse em sistema de gestão versus faixa de faturamento anual.

\begin{tabular}{|c|c|c|c|c|}
\hline \multirow{2}{*}{$\begin{array}{c}\text { Interesse em sistema } \\
\text { informatizado de gestão }\end{array}$} & \multicolumn{3}{|c|}{ Faixa de faturamento anual } & \multirow{2}{*}{$\begin{array}{l}\text { Total por } \\
\text { interesse }\end{array}$} \\
\hline & $\begin{array}{c}\text { Até } \\
\text { R\$ } 1 \text { milhão }\end{array}$ & $\begin{array}{c}\text { Entre } \\
\text { R\$ } 1 \text { e } 5 \text { milhões }\end{array}$ & $\begin{array}{c}\text { Entre } \\
\text { R\$ } 5 \text { e } 20 \text { milhões }\end{array}$ & \\
\hline Não & 3 & 1 & 2 & 6 \\
\hline $\operatorname{Sim}$ & 13 & 10 & 1 & 24 \\
\hline Total por faturamento & 16 & 11 & 3 & 30 \\
\hline
\end{tabular}

Tabela 23 - Interesse em sistema de gestão versus nível de automação.

\begin{tabular}{lcccc}
\hline \multirow{2}{*}{$\begin{array}{c}\text { Interesse em sistema } \\
\text { informatizado de gestão }\end{array}$} & Baixo & Intermediário & Alto & \multirow{2}{*}{$\begin{array}{c}\text { Total por } \\
\text { interesse }\end{array}$} \\
\cline { 2 - 5 } Não & 0 & 5 & 1 & 6 \\
Sim & 5 & 17 & 2 & 24 \\
Total por nível de automação & 5 & 22 & 3 & 30 \\
\hline
\end{tabular}


As empresas que consideram elevado o nível de concorrência do mercado apresentam porcentual elevado de interesse em sistema informatizado de gestão (Tabela 24) e também interesse em automação, ao passo que empresas que consideram baixa a concorrência apresentam porcentual bastante inferior (40\%, muito abaixo dos $88 \%$ das empresas que consideram alta a concorrência).

Como ocorreu com interesse em automação, fundições cujos clientes pertencem aos ramos automobilístico e metal-mecânico apresentam proporção bastante elevada de interesse em sistema informatizado de gestão (67\% e $88 \%$, respectivamente - Tabela 25).

Independentemente de o faturamento ser pequeno ou médio, os fatores que mais afetam a decisão de investir em automação e/ou sistemas informatizados de gestão são disponibilidade de recursos financeiros da empresa, perspectiva de crescimento da economia e volume de produção (Tabela 26). O mesmo ocorre para a produção em lotes pequenos e médios (Tabela 27). Verificamos que em apenas duas empresas o nível médio de instrução é apenas leitura ("saber ler", Tabela 28). Ambas pertencem à cidade de São Carlos. Curiosamente, apesar de São Carlos ser considerado um centro de alta tecnologia, em $40 \%$ de suas fundições é elevado o porcentual de mãode-obra que sabe apenas ler (Tabela 28).

Para a determinação do nível de informatização relativa seguimos os passos descritos por Fernandes \& Mulato (1998), levando em consideração a quantidade e o tipo de computadores, a existência ou não de Workstation e a quantidade de trabalhadores na empresa.

$O$ índice de informatização foi classificado entre 1 e 5 , sendo atribuído 1 ao nível de informatização mais baixo e 5 ao mais elevado. À medida que o faturamento anual aumenta, cresce o nível de informatização relativa (Tabela 29).

Das empresas com faturamento anual de até R \$ 1 milhão, 87,5\% situam-se nos níveis mais baixos de informatização relativa (1 e 2), enquanto para as demais faixas de faturamento anual esse porcentual passa para $81,8 \%$ (faturamento entre R\$ 1 e 5 milhões) e para $33,3 \%$ (faturamento entre $\mathrm{R} \$ 5$ e 20 milhões).

Tabela 24 - Interesse em sistema de gestão versus nível de concorrência.

\begin{tabular}{lccc}
\hline \multirow{2}{*}{$\begin{array}{c}\text { Interesse em sistema } \\
\text { informatizado de gestão }\end{array}$} & \multicolumn{2}{c}{ Nível de concorrência } & Total por \\
\cline { 2 - 3 } interesse
\end{tabular}

Tabela 25 - Interesse em sistema de gestão versus principal ramo dos clientes.

\begin{tabular}{lccccc}
\hline $\begin{array}{c}\text { Interesse em sistema } \\
\text { informatizado de } \\
\text { gestão }\end{array}$ & Automobilístico & $\begin{array}{c}\text { Indústria } \\
\text { química }\end{array}$ & Alimentos & Metal-mecânica & $\begin{array}{c}\text { Construção } \\
\text { civil }\end{array}$ \\
\cline { 2 - 6 } & 3 & 1 & 0 & 2 & 0 \\
Não & 6 & 1 & 2 & 14 & 1 \\
Sim & & & & & \\
\hline
\end{tabular}


Tabela 26 - Investimento em automação e/ou sistema informatizado de gestão versus faixa de faturamento anual.

\begin{tabular}{lccc}
\hline \multirow{2}{*}{ Investimento depende: } & \multicolumn{3}{c}{ Faixa de faturamento } \\
\cline { 2 - 4 } & $\begin{array}{c}\text { Menor que } \\
\text { R\$ 1 milhão }\end{array}$ & $\begin{array}{c}\text { Entre } \\
\text { R \$ 1 e 5 milhões }\end{array}$ & $\begin{array}{c}\text { Entre } \\
\text { \$ 5 20 milhões }\end{array}$ \\
\hline Disponibilidade de recursos financeiros da empresa & 11 & 11 & 1 \\
Perspectiva de crescimento da economia & 6 & 7 & 0 \\
Volume de produção & 8 & 5 & 1 \\
Nível tecnológico do mercado concorrencial & 4 & 3 & 0 \\
Qualidade da mão-de-obra & 4 & 2 & 1 \\
Informações sobre automação industrial & 1 & 2 & 0 \\
Informações sobre sistemas informatizados de gestão & 1 & 2 & 0 \\
da produção & & & \\
\hline
\end{tabular}

Tabela 27 - Investimento em automação e/ou sistema informatizado de gestão versus tamanho médio de lote.

\begin{tabular}{lcccc}
\hline \multirow{2}{*}{ Investimento depende: } & \multicolumn{3}{c}{ Tamanho médio de lote } \\
\cline { 2 - 5 } & Unitário & Pequeno & Médio & Grande \\
\hline Disponibilidade de recursos financeiros da empresa & 1 & 17 & 4 & 1 \\
Perspectiva de crescimento da economia & 1 & 8 & 4 & 0 \\
Volume de produção & 0 & 9 & 5 & 0 \\
Nível tecnológico do mercado concorrencial & 0 & 7 & 0 & 0 \\
Qualidade da mão-de-obra & 1 & 5 & 0 & 0 \\
Informações sobre automação industrial & 0 & 3 & 0 & 0 \\
Informações sobre sistemas informatizados de gestão & 0 & 2 & 1 & \\
da produção & & & \\
\hline
\end{tabular}

Quando observamos os níveis mais elevados de informatização relativa (4 e 5) vemos que $6,2 \%$ das empresas com faturamento anual de até R \$ 1 milhão situam-se nesse nível, enquanto para as demais faixas de faturamento anual esse porcentual passa para 18,2\% (faturamento entre $\mathrm{R} \$ 1$ e 5 milhões) e para 33,3\% (faturamento entre $\mathrm{R} \$ 5$ e 20 milhões). Porém, no geral, o nível de informatização é baixo: $80 \%$ das empresas possuem nível 1 ou 2 de informatização relativa, o que pode, nesses casos, dificultar a implantação de um sistema informatizado de gestão. Por meio da Tabela 30 constata-se tendência de empresas com um nível mais alto de automação também apresentarem um nível mais alto de informatização. Quanto maior o faturamento (Tabela 31), maior o nível de automação (Tabela 32); ou quanto melhor a tendência dos negócios (Tabela 33), maior o uso de redes locais no escritório. Outro aspecto que pode ser comparado para verificar o emprego dos recursos de informática pela empresa é a utilização desses equipamentos no chão de fábrica, o que exigiria menos tempo para acessar as informações necessárias para o processo e também para atualizá-las quando necessário. 
Tabela 28 - Nível de instrução médio da mão-de-obra direta versus cidade.

\begin{tabular}{lccc}
\hline \multirow{2}{*}{ Cidade } & \multicolumn{2}{c}{ Nível de instrução médio da mão-de-obra direta } & \multirow{2}{*}{ Total por cidade } \\
\cline { 2 - 3 } & Sabe ler & Sabe ler e escrever & \\
\hline Americana & 0 & 1 & 1 \\
Araraquara & 0 & 1 & 1 \\
Elias Fausto & 0 & 1 & 1 \\
Indaiatuba & 0 & 4 & 4 \\
Itu & 0 & 4 & 4 \\
Leme & 0 & 2 & 2 \\
Limeira & 0 & 3 & 3 \\
Monte Alto & 0 & 1 & 1 \\
Piracicaba & 0 & 7 & 7 \\
São Carlos & 2 & 3 & 5 \\
Sumaré & 0 & 1 & 1 \\
Total por nível de instrução & 2 & 28 & 30 \\
\hline
\end{tabular}

Tabela 29 - Nível de informatização versus faixa de faturamento anual.

\begin{tabular}{ccccc}
\hline \multirow{2}{*}{$\begin{array}{c}\text { Nível de informatização } \\
\text { relativa }\end{array}$} & \multicolumn{3}{c}{ Faixa de faturamento anual } & Total por nível de \\
\cline { 2 - 4 } & $\begin{array}{c}\text { Até } \\
\text { R \$ 1 milhão }\end{array}$ & $\begin{array}{c}\text { Entre } \\
\text { R\$ 1 e 5 milhões }\end{array}$ & $\begin{array}{c}\text { Entre } \\
\text { R 5 5 20 milhões }\end{array}$ & \\
\hline 1 & 8 & 5 & 0 & 13 \\
2 & 6 & 4 & 1 & 11 \\
3 & 1 & 0 & 1 & 2 \\
4 & 1 & 2 & 0 & 3 \\
5 & 0 & 0 & 1 & 1 \\
Total por faixa de faturamento & 16 & 11 & 3 & 30 \\
\hline
\end{tabular}

Tabela 30 - Nível de informatização versus nível de automação.

\begin{tabular}{ccccc}
\hline $\begin{array}{c}\text { Nível de } \\
\text { informatização relativa }\end{array}$ & Baixo & Nível de automação & $\begin{array}{c}\text { Total por nível de } \\
\text { informatização }\end{array}$ \\
\hline 1 & 3 & 10 & Alto & 13 \\
2 & 2 & 8 & 0 & 11 \\
3 & 0 & 2 & 1 & 2 \\
4 & 0 & 2 & 0 & 3 \\
5 & 0 & 0 & 1 & 1 \\
\hline
\end{tabular}


Tabela 31 - Ligação em rede no escritório versus faixa de faturamento anual.

\begin{tabular}{lcccc}
\hline \multirow{2}{*}{ Rede local no escritório } & \multicolumn{3}{c}{ Faixa de faturamento anual } & Total por ligação \\
\cline { 2 - 5 } & $\begin{array}{c}\text { Até } \\
\text { R 1 milhão }\end{array}$ & $\begin{array}{c}\text { Entre } \\
\text { R\$ 1 e 5 milhões }\end{array}$ & $\begin{array}{c}\text { Entre } \\
\mathbf{R} \mathbf{5} \text { e 20 milhões }\end{array}$ & \\
\hline Não & 11 & 4 & 0 & 15 \\
Sim & 5 & 7 & 3 & 15 \\
Total por faixa de faturamento & 16 & 11 & 3 & 30 \\
\hline
\end{tabular}

Tabela 32 - Ligação em rede no escritório versus nível de automação.

\begin{tabular}{lcccc}
\hline \multirow{2}{*}{ Rede local no escritório } & \multicolumn{3}{c}{ Nível de automação } & $\begin{array}{c}\text { Total por ligação de } \\
\text { rede local }\end{array}$ \\
\cline { 2 - 4 } & Baixo & Intermediário & Alto & 15 \\
Não & 1 & 13 & 1 & 15 \\
Sim & 4 & 9 & 2 & 30 \\
Total por nível de automação & 5 & 22 & 3 & \\
\hline
\end{tabular}

Tabela 33 - Ligação em rede no escritório versus tendência dos negócios da empresa.

\begin{tabular}{lccccc}
\hline \multirow{2}{*}{ Rede local no escritório } & \multicolumn{3}{c}{ Tendência dos negócios da empresa } & \multirow{2}{*}{ Total } \\
\cline { 2 - 5 } & Crescimento rápido Em crescimento & Estável & Em declínio & \\
\hline Não & 0 & 6 & 8 & 1 & 15 \\
Sim & 2 & 8 & 5 & 0 & 15 \\
Total por tendência & 2 & 14 & 13 & 1 & 30 \\
\hline
\end{tabular}

Para tanto é indispensável o uso de redes locais interligando o escritório ao chão de fábrica ou ainda interligando internamente as diferentes máquinas instaladas no chão de fábrica. Construímos tabelas para verificar como varia a utilização de rede local no chão de fábrica para diferentes fatores, como faturamento da empresa, nível de automação, etc. Pudemos observar o seguinte:

- Quanto maior o faturamento, maior o uso de rede local no chão de fábrica (Tabela 34).

- As empresas com baixo nível de automação não utilizam rede local no chão de fábrica (Tabela 35) e das com nível alto de automação apenas 33\% possuem rede local no chão de fábrica. Das empresas com nível intermediário de automação $18 \%$ possuem rede local no chão de fábrica.

- Para as empresas com tendência de declínio nos negócios não foi constatada presença de rede local no chão de fábrica (Tabela 36). Para as estáveis, $8 \%$ possuem rede local no chão de fábrica. Para as empresas em crescimento, $21 \%$, e para as em crescimento rápido, $50 \%$. 
Tabela 34 - Ligação em rede no chão de fábrica versus faixa de faturamento anual.

\begin{tabular}{lcccc}
\hline \multirow{2}{*}{$\begin{array}{c}\text { Rede local no } \\
\text { chão de fábrica }\end{array}$} & \multicolumn{3}{c}{ Faixa de faturamento anual } & \multirow{2}{*}{ Total } \\
\cline { 2 - 4 } & $\begin{array}{c}\text { Até } \\
\text { R \$ 1 milhão }\end{array}$ & $\begin{array}{c}\text { Entre } \\
\text { R\$ 1 e 5 milhões }\end{array}$ & $\begin{array}{c}\text { Entre } \\
\text { R\$ 5 e 20 milhões }\end{array}$ & \\
\hline Não & 16 & 9 & 0 & 25 \\
Sim & 0 & 2 & 3 & 5 \\
Total por faixa de faturamento & 16 & 11 & 3 & 30 \\
\hline
\end{tabular}

Tabela 35 - Ligação em rede no chão de fábrica versus nível de automação.

\begin{tabular}{|c|c|c|c|c|}
\hline \multirow{2}{*}{$\begin{array}{l}\text { Rede local no } \\
\text { chão de fábrica }\end{array}$} & \multicolumn{3}{|c|}{ Nível de automação } & \multirow{2}{*}{ Total } \\
\hline & Baixo & Intermediário & Alto & \\
\hline Não & 5 & 18 & 2 & 25 \\
\hline Sim & 0 & 4 & 1 & 5 \\
\hline Total por nível de automação & 5 & 22 & 3 & 30 \\
\hline
\end{tabular}

Tabela 36 - Ligação em rede no chão de fábrica versus tendência dos negócios da empresa.

\begin{tabular}{lcccccc}
\hline & $\begin{array}{c}\text { Rede local no } \\
\text { chão de fábrica }\end{array}$ & \multicolumn{3}{c}{ Tendência dos negócios da empresa } & \multirow{2}{*}{ Total } \\
\cline { 2 - 5 } & Crescimento rápido Em crescimento & Estável & Em declínio & \\
\hline Não & 1 & 11 & 12 & 1 & 25 \\
Sim & 1 & 3 & 1 & 0 & 5 \\
Total por tendência & 2 & 14 & 13 & 1 & 30 \\
\hline
\end{tabular}

Pudemos constatar, a partir das considerações feitas a respeito da utilização dos recursos de informática da empresa, que, salvo exceções, é bastante baixo o emprego dos recursos de informática existentes na melhoria das condições do trabalho, tanto no escritório quanto, principalmente, no chão de fábrica, onde tudo é feito de forma muito manual: ordens de produção e ordens de compra ainda são manuscritas.

A parte contábil dessas empresas é, muitas vezes, terceirizada, portanto, muitos recursos de informática que podem não estar sendo devidamente aproveitados dentro das empresas são compensados (nessa área contábil) por serviços terceirizados. Tabelas foram construídas para tentar identificar os tipos e características das empresas que possuem uma linha de contato entre fornecedores e/ou clientes por meio de rede (Internet, por exemplo). A partir dessas tabelas, aqui omitidas por questão de espaço, verificamos:

Empresas com maior faturamento anual utilizam mais a rede para comunicação entre fornecedores e também entre clientes do que empresas com faturamento mais baixo. Esse porcentual vai decrescendo à medida que a faixa de faturamento anual diminui. 
Para o nível de automação em empresas cujos níveis são intermediários, é maior o porcentual delas com ligação por rede entre fornecedores e também entre clientes do que nas empresas com nível baixo e alto. É interessante observar que as empresas com nível alto não possuem ligação por rede entre fornecedores nem entre clientes. Isso nos mostra que internamente elas são mais automatizadas, porém para contatos externos (entre clientes ou fornecedores) ainda utilizam exclusivamente contato direto, ou ainda telefone ou fax, em vez de agilizá-lo com o uso de rede entre seus clientes e entre seus fornecedores.

Por tendência dos negócios, 50\% das empresas em crescimento ou em crescimento rápido utilizam ligação de rede para comunicação entre clientes e/ou fornecedores. Entre empresas em declínio nenhuma utiliza rede para comunicação entre clientes e/ou fornecedores. Já para as empresas em situação estável, $8 \%$ utilizam tais recursos.

\section{Projetos de melhoria e síntese dos problemas e necessidades na área produtiva}

Depois de caracterizar o segmento estudado (visão geral, porte, tipos de ligas, tamanho de lotes, nível de automação e interesse em automação e em sistemas informatizados de gestão), nesta seção analisamos os projetos de melhoria na área produtiva do segmento focalizado e apresentamos uma síntese dos problemas e necessidades na área produtiva que os entrevistados apontaram como críticos.

\subsection{Projetos de melhoria}

Nas Tabelas 37, 38, 39 e 40 estão apresentadas informações sobre projetos de melhoria. A importância dos projetos corresponde à importância dada pela empresa ao projeto correspondente, e sua escala varia de 1 (sem importância) a 5 (muito importante). Os projetos foram agrupados em duas partes: em uma parte há distinção entre implantação em versão manual e versão informatizada (Tabelas 37 e 39) e em outra não há tal distinção (Tabelas 38 e 40). Três índices foram utilizados para a ordenação dos projetos de melhoria, a saber:

$\mathrm{I}_{1}=$ Valor mínimo $=\bar{X}-3 S$

$\mathrm{I}_{2}=$ Índice de importância $=\bar{X} / \mathrm{S}$ (quanto maior a média e menor o $S$, maior é o índice)

$\mathrm{I}_{3}=$ Variabilidade relativa $=S / \bar{X}$, em que a média $(\bar{X})$ corresponde à importância média do projeto de melhoria; $S$ é o desvio-padrão da importância; e $\mathrm{I}_{1}, \mathrm{I}_{2}$ e $\mathrm{I}_{3}$ são os índices utilizados para a classificação dos projetos.

$\mathrm{I}_{1}$ é o primeiro índice utilizado para a classificação. Em caso de valores iguais, $\mathrm{I}_{2}$ é utilizado como critério de desempate. Esses dois índices são classificados do maior para o menor valor. Paralelamente a isso, o índice $\mathrm{I}_{3}$ indica a variabilidade relativa das medidas, e é classificado do menor para o maior valor, ou seja, da menor variabilidade relativa para a maior. Portanto, para um projeto ser mais consistentemente importante, ele deve apresentar os maiores valores para os dois primeiros índices e o menor valor para o terceiro índice.

Um exemplo de como esses índices serão utilizados na ordenação dos projetos de melhoria pode ser visto ao considerar dois projetos quaisquer com importância média 4,6 e 4,0 e desvio-padrão de 0,4 e de 0,3 , respectivamente. Calculando os dois índices $\left(\mathrm{I}_{1}\right.$ e $\mathrm{I}_{2}$ ), temos que para o primeiro projeto (importância média de 4,6 e desvio-padrão de $0,4)$ o valor dos índices é 3,4 $\left(\mathrm{I}_{1}\right)$ e 11,5 $\left(\mathrm{I}_{2}\right)$, enquanto para o segundo projeto o valor dos índices é 3,1 e 13,33, respectivamente. Se apenas o segundo índice fosse utilizado, o segundo projeto ocuparia posição relativa superior à do primeiro, embora consideremos o primeiro projeto mais importante, pois uma 
diferença da média bem mais significativa que a diferença do desvio foi verificada. Logo, é preferível que o primeiro projeto ocupe posição mais elevada que o segundo.

Há outro exemplo da utilização desses índices, mas agora considerando o critério de desempate entre dois projetos, um com média 4,6 e desvio 0,4 e outro com média 4,3 e desvio 0,3 . O valor dos índices para o primeiro projeto é 3,4 e 11,5 ( $\mathrm{I}_{1}$ e $\mathrm{I}_{2}$, respectivamente) e para o segundo projeto é 3,4 e $14,33 \quad\left(\mathrm{I}_{1}\right.$ e $\mathrm{I}_{2}$, respectivamente). Dessa forma, ambos os projetos estão empatados, considerando o índice $\left(\mathrm{I}_{1}\right)$, mas, se considerarmos o índice $\left(\mathrm{I}_{2}\right)$ como critério para desempate, o segundo projeto (média 4,3 e desvio 0,3) ocupará posição mais elevada que o segundo.

Em caso de dois ou mais projetos apresentarem os mesmos valores para os 3 índices utilizados na classificação dos projetos de melhoria, empregaremos o posto médio. Por exemplo, se 3 projetos, apresentando os mesmos valores para os 3 índices de classificação, classificarem-se em 6으, 7ㅇ e $8^{\circ}$ lugares, o posto médio a ser adotado é $(6+7+8) / 3=7$. Ou seja, os 3 projetos aparecerão com a classificação 7 .

De forma geral, podemos afirmar que mais ajuda externa (Universidade, SENAI, consultoria) é desejada para os projetos com maior importância e que, devido a essa importância, já estão implantados ou estão para ser implantados nos próximos 3 anos na maioria das empresas (Tabelas 37 e 38).

Os projetos de melhoria identificados como de importância A (importância mais alta) são os relacionados com a melhoria da qualidade, melhoria da manufatura e do projeto do fundido e com a programação da produção. Ou seja, são projetos que têm relação direta ou indireta com a automação industrial ou com a informatização de processos de gestão. Porém, apenas 3,33\% das empresas (1 em 30) implantaram equipamentos automatizados controlados por computador e $30 \%$ pretendem implantar tais equipamentos automatizados num horizonte de 3 anos.
De todos os projetos de melhoria mostrados nas Tabelas 37 e 38, vale a pena ressaltar neste artigo: os projetos de programação da produção no geral apresentaram porcentual de implantação acima de $60 \%$ (considerando versões manual e informatizada) e importância média em torno de 4 (numa escala de 1 a 5), ou seja, importante.

Os projetos ligados à programação se dividem em dois grupos:

Os muito importantes: "Programação da produção visando à redução de refugos" (4을 lugar entre 32 projetos); "Programação da produção visando a melhor cumprimento de prazos" (6º lugar); "Programação da produção visando fechar os pedidos para faturar $(\$)$ o quanto antes" (7o lugar).

Os significativamente importantes: "Programação da produção para maximizar o volume de produção sujeito a restrições de espaço disponível" (15o lugar); "Programação da produção visando a melhor utilização dos equipamentos para aumentar a produção" (16음 lugar); "Programação da produção visando à redução de consumo de energia" (19o lugar).

Essas informações são extremamente úteis para o desenvolvimento de um sistema de programação da produção adequado ao segmento em estudo. O 16으 lugar ("Programação da produção visando a melhor utilização dos equipamentos para aumentar a produção") mostra que tais empresas não acreditam que equipamento parado represente prejuízo certo, idéia que predominou até os anos 70. As empresas estão preocupadas principalmente com a redução de refugos (que impacta os custos e pode impactar a qualidade dos produtos recebidos pelos clientes), com o atendimento dos prazos e em faturar o quanto antes (4ㅇ, 6o e 7o lugar em importância entre 32 projetos, respectivamente). Outros projetos, como "prototipagem rápida" e "uso de sistema CAD para modelação", por exemplo, não têm grande importância para as empresas do segmento de fundições de mercado, pois o modelo geralmente é fornecido pelo próprio cliente. 
Tabela 37 - Projetos de melhoria apontados pelas empresas (parte 1).

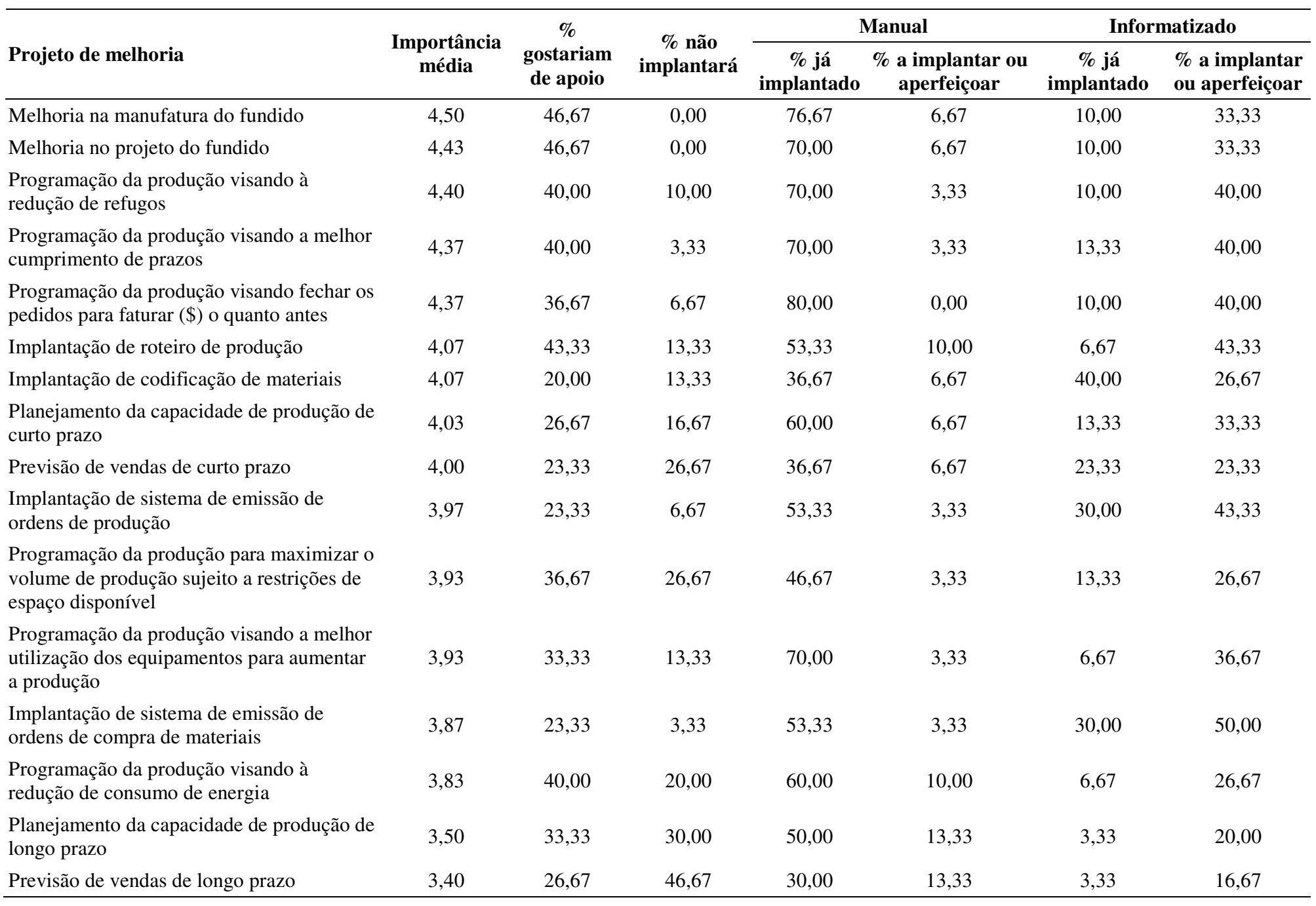


Tabela 38 - Projetos de melhoria apontados pelas empresas (parte 2).

\begin{tabular}{|c|c|c|c|c|c|}
\hline Projeto de melhoria & $\begin{array}{l}\text { Importância } \\
\text { média }\end{array}$ & $\begin{array}{l}\text { \% gostariam } \\
\text { de apoio }\end{array}$ & $\begin{array}{c}\text { \% não } \\
\text { implantará }\end{array}$ & \% já implantado & $\begin{array}{c}\% \text { a implantar ou } \\
\text { aperfeiçoar }\end{array}$ \\
\hline $\begin{array}{l}\text { Melhoria da qualidade dos produtos entregues aos } \\
\text { clientes }\end{array}$ & 4,60 & 53,33 & 3,33 & 83,33 & 60,00 \\
\hline $\begin{array}{l}\text { Redução das taxas de refugo ou retrabalho para } \\
\text { redução de custos }\end{array}$ & 4,40 & 43,33 & 13,33 & 56,67 & 56,67 \\
\hline Implantação da Gestão da Qualidade Total & 4,13 & 46,67 & 33,33 & 23,33 & 53,33 \\
\hline Implantação da ISO 9000 & 4,10 & 53,33 & 30,00 & 26,67 & 50,00 \\
\hline Implantação da Gestão de Processos & 3,90 & 60,00 & 23,33 & 23,33 & 63,33 \\
\hline $\begin{array}{l}\text { Software que defina as quantidades das matérias- } \\
\text { primas para atingir a composição a um mínimo } \\
\text { custo }\end{array}$ & 3,73 & 40,00 & 43,33 & 13,33 & 46,67 \\
\hline Redução de estoques de matérias-primas & 3,67 & 26,67 & 20,00 & 56,67 & 30,00 \\
\hline Software para simulação de solidificação & 3,63 & 56,67 & 53,33 & 0,00 & 46,67 \\
\hline Redução de estoques em processo & 3,60 & 20,00 & 40,00 & 36,67 & 26,67 \\
\hline $\begin{array}{l}\text { Implantação de Reengenharia de Processos de } \\
\text { Negócio }\end{array}$ & 3,30 & 46,67 & 63,33 & 3,33 & 36,67 \\
\hline Redução de estoques de produtos finais & 3,23 & 16,67 & 36,67 & 46,67 & 20,00 \\
\hline $\begin{array}{l}\text { Implantação de equipamentos automatizados } \\
\text { controlados por computador }\end{array}$ & 2,97 & 26,67 & 66,67 & 3,33 & 30,00 \\
\hline Redução no número de fornecedores & 2,90 & 20,00 & 40,00 & 40,00 & 33,33 \\
\hline Uso do sistema CAD para modelação & 2,87 & 26,67 & 66,67 & 10,00 & 23,33 \\
\hline Prototipagem rápida & 2,70 & 30,00 & 80,00 & 3,33 & 16,67 \\
\hline Aumento no número de fornecedores & 2,63 & 13,33 & 60,00 & 3,33 & 36,67 \\
\hline
\end{tabular}


Tabela 39 - Cruzamentos: projetos de melhoria (parte 1).

\begin{tabular}{|c|c|c|c|c|c|c|c|c|c|}
\hline \multirow[t]{2}{*}{ Projeto de melhoria } & \multicolumn{3}{|c|}{ Automação } & \multicolumn{4}{|c|}{$\begin{array}{l}\text { Tamanho } \\
\text { médio de lote }\end{array}$} & \multicolumn{2}{|c|}{$\begin{array}{l}\text { Concorrência/ } \\
\text { mercado }\end{array}$} \\
\hline & $\mathbf{P}$ & $\mathbf{M}$ & $\mathbf{G}$ & 1 & 2 & 3 & 4 & Pouca & Muita \\
\hline Melhoria na manufatura do fundido & 6,5 & 2 & 4 & 2 & 1 & 9 & 8,5 & 8 & 1 \\
\hline Melhoria no projeto do fundido & 12 & 1 & 8 & 8,5 & 2 & 10 & 1,5 & 5 & 4,5 \\
\hline $\begin{array}{l}\text { Programação da produção visando à redução } \\
\text { de refugos }\end{array}$ & 2,5 & 7 & 1,5 & 8,5 & 6 & 2 & 1,5 & 1,5 & 4,5 \\
\hline $\begin{array}{l}\text { Programação da produção visando a melhor } \\
\text { cumprimento de prazos }\end{array}$ & 2,5 & 4,5 & 4 & 2 & 4,5 & 2 & 8,5 & 5 & 2,5 \\
\hline $\begin{array}{l}\text { Programação da produção visando fechar os } \\
\text { pedidos para faturar (\$) o quanto antes }\end{array}$ & 2,5 & 4,5 & 4 & 2 & 4,5 & 2 & 8,5 & 5 & 2,5 \\
\hline Implantação de roteiro de produção & 5 & 3 & 10 & 16 & 3 & 4 & 8,5 & 14 & 6 \\
\hline Implantação de codificação de materiais & 8 & 13 & 6 & 8,5 & 14 & 6,5 & 8,5 & 5 & 12 \\
\hline $\begin{array}{l}\text { Planejamento da capacidade de produção de } \\
\text { curto prazo }\end{array}$ & 2,5 & 8 & 14,5 & 8,5 & 9,5 & 6,5 & 8,5 & 12 & 8 \\
\hline Previsão de vendas de curto prazo & 14 & 6 & 14,5 & 8,5 & 7 & 15,5 & 8,5 & 5 & 9 \\
\hline $\begin{array}{l}\text { Implantação de sistema de emissão de ordens } \\
\text { de produção }\end{array}$ & 13 & 10 & 10 & 8,5 & 9,5 & 13 & 8,5 & 12 & 11 \\
\hline $\begin{array}{l}\text { Programação da produção para maximizar o } \\
\text { volume de produção sujeito a restrições de } \\
\text { espaço disponível }\end{array}$ & 9,5 & 11 & 7 & 14,5 & 8 & 6,5 & 8,5 & 16 & 7 \\
\hline $\begin{array}{l}\text { Programação da produção visando a melhor } \\
\text { utilização dos equipamentos para aumentar a } \\
\text { produção }\end{array}$ & 9,5 & 9 & 14,5 & 8,5 & 11 & 6,5 & 8,5 & 1,5 & 10 \\
\hline $\begin{array}{l}\text { Implantação de sistema de emissão de ordens } \\
\text { de compra de materiais }\end{array}$ & 6,5 & 12 & 10 & 8,5 & 12,5 & 11,5 & 15 & 10 & 13 \\
\hline $\begin{array}{l}\text { Programação da produção visando à redução } \\
\text { de consumo de energia }\end{array}$ & 11 & 14 & 1,5 & 8,5 & 12,5 & 11,5 & 16 & 9 & 14 \\
\hline $\begin{array}{l}\text { Planejamento da capacidade de produção de } \\
\text { longo prazo }\end{array}$ & 16 & 15 & 12 & 14,5 & 15 & 14 & 8,5 & 15 & 15 \\
\hline Previsão de vendas de longo prazo & 15 & 16 & 14,5 & 8,5 & 16 & 15,5 & 8,5 & 12 & 16 \\
\hline
\end{tabular}

É pequena a porcentagem de empresas que já adquiriram "software para a simulação de solidificação" e "equipamentos automatizados controlados por computador". Isso se deve ao elevado capital necessário para tais implantações. Vale ressaltar que, de maneira geral, não compensa realizar a simulação da solidificação para peças pequenas feitas em pequenas quantidades; já para peças pequenas feitas em grandes quantidades o que se faz é um experimento real com uma pequena amostra. No caso de fundição de peças grandes, é bem conveniente realizar a simulação, já que, por exemplo, para fundir uma única peça de 5 toneladas, o tempo de resfriamento da peça real é muito grande e, se ela for refugada, haverá um impacto negativo considerável nos custos e no prazo de entrega. 
Tabela 40 - Cruzamentos: projetos de melhoria (parte 2).

\begin{tabular}{|c|c|c|c|c|c|c|c|c|c|}
\hline \multirow[t]{2}{*}{ Projeto de melhoria } & \multicolumn{3}{|c|}{ Automação } & \multicolumn{4}{|c|}{$\begin{array}{c}\text { Tamanho } \\
\text { médio de lote }\end{array}$} & \multicolumn{2}{|c|}{$\begin{array}{l}\text { Concorrência/ } \\
\text { mercado }\end{array}$} \\
\hline & $\mathbf{P}$ & M & $\mathbf{G}$ & 1 & 2 & 3 & 4 & Pouca & Muita \\
\hline $\begin{array}{l}\text { Melhoria da qualidade dos produtos entregues } \\
\text { aos clientes }\end{array}$ & 2 & 1 & 1 & 3 & 1 & 1 & 1,5 & 4 & 1 \\
\hline $\begin{array}{l}\text { Redução das taxas de refugo ou retrabalho para } \\
\text { redução de custos }\end{array}$ & 1 & 2 & 8 & 3 & 2 & 2 & 1,5 & 2 & 2 \\
\hline Implantação da Gestão da Qualidade Total & 6 & 3 & 15 & 3 & 4 & 4,5 & 8,5 & 1 & 4 \\
\hline Implantação da ISO 9000 & 5 & 5 & 3 & 3 & 3 & 8,5 & 8,5 & 14 & 3 \\
\hline Implantação da Gestão de Processos & 7 & 4 & 11 & 6 & 5 & 3 & 8,5 & 3 & 5 \\
\hline $\begin{array}{l}\text { Software que defina as quantidades das matérias- } \\
\text { primas para atingir a composição a um mínimo } \\
\text { custo }\end{array}$ & 8 & 6 & 14 & 3 & 7 & 6 & 8,5 & 12 & 6 \\
\hline Redução de estoques de matérias-primas & 4 & 7 & 10 & 9 & 8 & 8,5 & 8,5 & 7,5 & 9 \\
\hline Software para simulação de solidificação & 9 & 8 & 9 & 9 & 9 & 4,5 & 8,5 & 7,5 & 8 \\
\hline Redução de estoques em processo & 3 & 9 & 2 & 9 & 6 & 7 & 8,5 & 9 & 7 \\
\hline $\begin{array}{l}\text { Implantação de Reengenharia de Processos de } \\
\text { Negócio }\end{array}$ & 10 & 10 & 13 & 14,5 & 10 & 13 & 8,5 & 5 & 11 \\
\hline Redução de estoques de produtos finais & 13 & 13 & 4 & 9 & 11 & 16 & 8,5 & 16 & 10 \\
\hline $\begin{array}{l}\text { Implantação de equipamentos automatizados } \\
\text { controlados por computador }\end{array}$ & 16 & 14 & 7 & 14,5 & 14 & 14 & 8,5 & 6 & 13 \\
\hline Redução no número de fornecedores & 15 & 11 & 12 & 12 & 12 & 11,5 & 8,5 & 10 & 14 \\
\hline Uso do sistema CAD para modelação & 12 & 16 & 16 & 16 & 16 & 15 & 16 & 15 & 16 \\
\hline Prototipagem rápida & 14 & 15 & 5 & 9 & 15 & 11,5 & 15 & 13 & 15 \\
\hline Aumento no número de fornecedores & 11 & 12 & 6 & 13 & 13 & 10 & 8,5 & 11 & 12 \\
\hline
\end{tabular}

Dos projetos das Tabelas 39 e 40, vale a pena ressaltar neste artigo: para as empresas com o mais baixo nível de automação (P na Tabela 39), o planejamento da capacidade, juntamente com projetos de programação da produção, são os mais significativamente importantes. As condições precárias que essas empresas enfrentam (algumas delas utilizam fornos inadequados para a produção de determinados tipos de liga, com pouco ou nenhum controle de temperatura, resultando em sérios problemas com índices de refugo) contribuem para que esse quadro se estabeleça. Melhoria na manufatura e melhoria no projeto do fundido, que para as demais ocupam posições relativas mais elevadas, acabam recebendo menor importância em decorrência de limitações que as empresas com níveis mais baixos de automação apresentam e que contribuem para que outros projetos recebam maior importância. A implantação de equipamentos automatizados é um exemplo de projeto que ocupa posição relativa mais elevada nas empresas com baixo nível de automação do que nas demais empresas (Tabela 40), recebendo a mesma importância que a melhoria da manufatura do fundido. Por outro lado, as empresas com nível de automação mais alto ( $\mathrm{G}$ na Tabela 39) dão grande importância à programação da produção visando à redução do consumo de energia (entre os dois projetos mais significativamente importantes na Tabela 39), enquanto o planejamento da capacidade de produção de curto 
prazo ocupa uma das últimas posições [situação bem diferente da que ocorre nas empresas com baixo nível de automação ou com nível intermediário (M na Tabela 39) de automação, em que a programação da produção visando à redução do consumo de energia ocupa o $11^{\circ}$ e o 14ํ lugar, respectivamente].

Para as empresas com o mais alto nível de automação, os projetos com importância média mais elevada são novamente projetos relacionados à programação da produção (4 dos 8 mais importantes da Tabela 39: visando a melhor cumprimento dos prazos, visando fechar pedidos o quanto antes, visando à redução de refugos e visando à redução do consumo de energia). Os demais projetos são melhoria na manufatura do fundido e implantação de codificação de materiais, melhoria da qualidade dos produtos entregues e implantação da ISO 9000. Esses resultados são compatíveis com um postulado de Sipper \& Bulfin (1997) de que, quando temos um sistema de produção mais avançado, também devemos ter um sistema de PCP (Planejamento e Controle da Produção) mais avançado. Ainda, para as empresas com o mais alto nível de automação, o projeto redução de estoques de produtos finais ocupa posição relativa mais elevada que para as empresas dos demais níveis (4ํ lugar para empresas com nível alto e 13ํ lugar para as demais - Tabela 40).

Programação da produção para as empresas que trabalham com lotes unitários (tamanho 1 na Tabela 39) tem menos importância do que para os demais tamanhos de lote, quando a programação visa à redução de refugos ou à maximização da utilização do espaço. Porém, com exceção de programações visando a melhor cumprimento dos prazos e fechamento de pedidos para faturar o quanto antes, os projetos de programação da produção ganham a mesma importância que os projetos de implantação de sistemas de emissão de ordens, planejamento de capacidade de produção de curto prazo e previsão de vendas (de longo e de curto prazo), além de melhoria no projeto e na manufatura do fundido. Para as empresas que trabalham com lotes médios, os projetos de programação da produção são prioritários (os 3 mais significativamente importantes são projetos de programação da produção - Tabela 39).

Empresas que se consideram em um mercado com pouca concorrência apontam, diferentemente das demais, o projeto de programação da produção visando a melhor utilização de equipamentos entre os 2 projetos mais significativamente importantes. Previsão de vendas de curto prazo é outro projeto que se situa entre os mais importantes para as empresas que se consideram em um mercado com pouca concorrência ( $5^{\circ}$ na Tabela 39 ) e que para as demais empresas ocupa posição intermediária (9o lugar). Enquanto para as empresas que se consideram em um mercado com muita concorrência o projeto de melhoria da manufatura do fundido foi classificado como o mais significativamente importante, nas empresas que não se consideram em um mercado tão concorrido esse projeto ocupou posição intermediária ( $8^{\circ}$ lugar), dando mais importância a outros projetos, como previsão de vendas de curto prazo, por exemplo. Podemos observar que as empresas com pouca concorrência têm condições de realizar e dar maior importância à previsão de vendas de curto prazo do que as empresas com muita concorrência, visto que a oscilação das vendas tende a ser maior nessas empresas do que nas empresas com pouca concorrência.

Para as empresas que trabalham com lotes unitários (1 na Tabela 40), o projeto de implantação de software para a definição das quantidades de matérias-primas para que a composição da liga seja atingida a um custo mínimo ocupa o 3ำ lugar em importância, o que é coerente, já que o lote a ser produzido é de apenas uma peça e a quantidade do material importa mais nesse caso do que no caso de se trabalhar com lotes maiores (em que esse projeto ocupa as posições 7,6 e 8,5 para as empresas que trabalham com lotes pequenos (2), médios (3) e grandes (4), respectivamente).

Pelas análises relativas aos projetos de melhoria, vemos que, em geral, quanto mais importante o projeto para as diferentes categorias 
de empresas, menor é a variância da importância. Isso nos mostra que, no geral, projetos importantes para uma categoria de empresas são importantes para a categoria toda. Uma das poucas exceções é a relativa a projetos como implantação de ISO 9000 e Gestão da Qualidade Total que, embora tenham alta importância, sua variância é, em geral, maior que a dos demais de importância também alta. Isso mostra a diferente importância que algumas empresas dão a esse tipo de projeto de qualidade. Para muitas empresas, esses projetos significam o mesmo que o projeto melhoria da qualidade dos produtos entregues aos clientes, porém este último muitas vezes é realizado de forma subjetiva, devido à não utilização de procedimentos e sistemas de qualidade, como no caso da certificação ISO 9000, por exemplo. Além disso, a alta variância de tais projetos pode estar relacionada à avaliação subjetiva e variável de empresa para empresa da relação custos/benefícios.

\subsection{Problemas e necessidades da área produtiva}

Para concluir, mostrando de forma definitiva a relevância dos trabalhos que levem à melhoria dos equipamentos e dos processos de fabricação e de gestão, o que envolve diretamente a automação industrial e os sistemas informatizados de PCP, apresentamos a Tabela 41, na qual os principais problemas e necessidades relativos à produção foram agrupados em 6 categorias, segundo classificação contida em Zaccarelli (1990). É importante destacar que até 3 problemas e necessidades relativos à produção poderiam ser apontados pelas empresas.

Os problemas com equipamentos e com processos de fabricação aparecem como os mais relevantes, visto o elevado porcentual de empresas que apontaram essa categoria como problema/necessidade da área produtiva $(66,67 \%$ na Tabela 41). Mão-de-obra (treinamento e produtividade) foi a segunda categoria mais apontada pelas empresas da amostra como problema/necessidade da área produtiva $(36,67 \%$ na Tabela 41). Essas duas categorias refletem as condições de trabalho encontradas nas fundições de mercado: baixa qualificação da mão-de-obra e deficiências em equipamentos.

\section{Conclusões}

Os principais objetivos deste trabalho são verificar até que ponto a automação pode ser importante para o segmento de fundições de mercado do interior do Estado de São Paulo pertencentes aos (ou à vizinhança dos) 5 principais pólos (Piracicaba, Indaiatuba, Limeira, São Carlos e Itu); ou e até que ponto processos de decisão mais racionais, baseados em sistemas informatizados de gestão da produção, podem ser importantes para esse segmento.

Com este trabalho, esperamos que um conjunto de informações úteis seja fornecido para que pesquisas aplicadas às necessidades do segmento sejam conduzidas, proporcionando contribuições para o avanço de pesquisas acadêmicas mais focadas nos aspectos que despertem mais o interesse das empresas. Dessa forma, os resultados de pesquisas acadêmicas poderão ser mais facilmente disseminados para as empresas.

Embora 73,3\% das empresas da amostra tenham interesse em automação industrial (Quadro 1), o nível de automação que o segmento (fundições de mercado do interior do Estado de São Paulo, pertencentes aos 5 principais pólos e suas imediações) apresenta, em termos de equipamentos automatizados, é bastante baixo. $\mathrm{O}$ sistema de produção operando sob encomenda e produzindo um grande número de pedidos vindos, em geral, de um grande número de clientes desfavorece a implantação de certos tipos de equipamentos para a automatização da produção, se comparado com fundições cativas (que produzem grandes quantidades de produtos para um único cliente) ou com fundições que produzem produtos mais padronizados. 
Tabela 41 - Principais problemas e necessidades relativos à produção das empresas.

\begin{tabular}{lc}
\hline Principais problemas e necessidades relativos à produção & \% de empresas \\
\hline Equipamentos e problemas de processo de fabricação & 66,67 \\
Treinamento e produtividade da mão-de-obra & 36,67 \\
Planejamento e controle da produção & 30,00 \\
Qualidade & 30,00 \\
Suprimentos & 16,67 \\
Instalações industriais & 13,33 \\
\hline
\end{tabular}

A não realização de projetos de modelos para as peças que serão fundidas (o que normalmente fica a cargo dos clientes, cabendo às fundições apenas projetos de canais e massalotes, ou ainda pequenos reparos em modelos danificados) acaba refletindo em baixa porcentagem de empresas que implantaram (10\%) ou que irão implantar/aperfeiçoar sistemas CAD em um período de três anos $(23,33 \%)$ - ver Tabela 38 .

Quando o assunto é sistema informatizado, o interesse também é elevado (80\%, ver Quadro 1). Porém, situação análoga à dos equipamentos automatizados ocorre: baixa porcentagem de empresas que implantaram em versão informatizada os projetos relativos a sistemas de emissão de ordens de compra (30\%), ordens de produção $(30 \%)$, roteiro de produção $(6,67 \%)$ e os projetos para programação da produção $(13,33 \%$, maior porcentual entre os projetos de programação da produção). Isso pode ser verificado na Tabela 37. Por meio desses projetos, pode-se concluir que é baixa a utilização de sistemas informatizados para a gestão.

Portanto, verificamos, por meio de análises feitas nas Seções 2 e 3, que o segmento é carente tanto em equipamentos automatizados quanto em sistemas informatizados de gestão. Essas questões são problemas potenciais a serem explorados. As empresas reconhecem a importância e a necessidade de tais equipamentos ou sistemas. Dos problemas e necessidades apontados pelas empresas da amostra (Tabela 41), equipamentos e processos de fabricação são os mais citados $(66,67 \%)$, refletindo a precariedade dos equipamentos e o baixo nível de automação dos equipamentos. Além disso são carências para as empresas (em ordem de importância): treinamento e produtividade da mão-de-obra (crítico para 37\% das empresas), PCP (30\%), qualidade $(30 \%)$, suprimentos $(17 \%)$ e instalações industriais (13\%). Os problemas relacionados à mão-de-obra (treinamento e produtividade), que são a segunda categoria mais apontada pelas empresas como problemas ou necessidades da área produtiva $(36,67 \%$ na Tabela 41), refletem, juntamente com equipamentos, as condições de trabalho encontradas nas fundições de mercado: baixa qualificação da mão-de-obra e deficiências em equipamentos.

Outras conclusões são sumarizadas a seguir:

- As empresas que se situam entre as com mais baixo nível de automação (tanto de equipamentos quanto de processos) reconhecem a necessidade de equipamentos automatizados (a Tabela 17 apresenta o interesse em automação para as empresas com diferentes níveis de automação e a Tabela 40 mostra a posição relativa do projeto implantação de equipamentos automatizados para as empresas com diferentes níveis de automação), mas a escassez de recursos financeiros, limitações de volume de produção e a perspectiva de crescimento da economia são os fatores que mais restringem os investimentos, tanto em automação quanto em implan- 
tação de sistemas informatizados de gestão. Isso é apontado independentemente da faixa de faturamento anual das empresas (Tabela 26).

- O nível de informatização é muito baixo. A comunicação com os clientes, recebimento de pedidos, etc. é feito por meio de telefone/ fax, quando não por contato direto com o cliente. A não utilização de recursos de informática nas empresas atualmente representa desvantagem competitiva para elas, pois as informações circulam muito mais lentamente e as análises de desempenho e o tempo de resposta das empresas são muito demorados.

- Interesse em automação e em sistemas informatizados de gestão são coincidentes. Empresas que estão melhor posicionadas nesses aspectos também estão melhor posicionadas quanto à tendência dos negócios. Porém, como foi mostrado anteriormente, a automação das fundições é baixa no que se refere a equipamentos. $\mathrm{O}$ que se tem de mais automatizado são fornos com melhor controle de temperatura, ou ainda máquinas para a moldagem.

- Algumas empresas implantaram sistemas para a recuperação da areia de fundição. Esses sistemas não são implantados com o objetivo de reduzir o número de trabalhadores na produção, mas, antes, como uma preocupação ambiental ou como um instrumento para diminuir custos com a redução das compras de areia para fundição.

- As empresas se restringem ao mercado nacional e enfrentam os custos mais baixos (tanto de matéria-prima quanto de mão-de-obra) das empresas do Estado de Minas Gerais. Provavelmente, esse foi um fator que contribuiu para que tantas empresas que eram cadastradas na ABIFA em maio de 1999 (ABIFA, 1999) estivessem fechadas no primeiro semestre de 2000, pois além dessa concorrência, as fundições de mercado enfrentam vários problemas apresentados na Seção 3 ("Projetos de melhoria e síntese dos problemas e necessidades na área produtiva").

- No interior do Estado de São Paulo não existem fundições de mercado com mais de 250 funcionários. As grandes fundições são cativas de si mesmas ou são fornecedoras cativas de algum (alguns) grande(s) cliente(s).

- O faturamento/trabalhador é muito mais função da tecnologia do produto (no caso de fundição corresponde ao know-how requerido para operar com determinados aços especiais) do que da tecnologia do processo de fabricação.

- Nossa atenção foi despertada para o fato de alta porcentagem de empresas que produzem em pequenos lotes apresentarem interesse em automação (Tabela 18). Porém, esse interesse é limitado a certos aspectos específicos do processo, por exemplo, forno com controles mais automatizados, melhor controle da temperatura ou, ainda, aparelhos mais automatizados para seus laboratórios de análise.

- Curiosamente, apesar de São Carlos ser considerado um centro de alta tecnologia, em $40 \%$ de suas fundições é elevado o porcentual de mão-de-obra que sabe apenas ler (Tabela 28).

- Em empresas cujos negócios estão em declínio não foi constatada presença de rede local no chão de fábrica (Tabela 36). Entre as estáveis, $8 \%$ possuem rede local no chão de fábrica. Para as empresas em crescimento, $21 \%$, e para as em crescimento rápido, $50 \%$. Além disso, $50 \%$ das empresas em crescimento ou em crescimento rápido utilizam ligação de rede para comunicação entre clientes e/ou fornecedores, enquanto nenhuma das empresas em declínio emprega rede para comunicação entre clientes e/ou fornecedores e $8 \%$ das empresas em situação estável utilizam tais recursos. 
- Os projetos de melhoria identificados como de importância A (importância mais alta) são os relacionados com a melhoria da qualidade, melhoria da manufatura e do projeto do fundido e com a programação da produção. Ou seja, são projetos que têm relação direta ou indireta com a automação industrial ou com a informatização de processos de gestão da produção.

- A importância da programação da produção vai de alta para os critérios "Programação da produção visando à redução de refugos" (4ํ lugar entre 32 projetos), "Programação da produção visando a melhor cumprimento de prazos" (6- lugar) e "Programação da produção visando fechar os pedidos para faturar $(\$)$ o quanto antes" (7o lugar) até significativamente importante para os critérios "Programação da produção para maximizar o volume de produção sujeito a restrições de espaço disponível" (15º lugar), "Programação da produção visando a melhor utilização dos equipamentos para aumentar a produção" (16- lugar) e "Programação da produção visando à redução de consumo de energia" (19º lugar).
Essas informações são extremamente úteis para o desenvolvimento de um sistema de programação da produção adequado ao segmento em estudo. O primeiro autor deste artigo é orientador de uma tese de doutorado que leva em conta essas informações.

- Pelas análises relativas aos projetos de melhoria, vemos que, em geral, quanto mais importante o projeto para as diferentes categorias de empresas, menor é a variância da importância. Isso nos mostra que, no geral, projetos importantes para uma categoria de empresas são importantes para a categoria toda.

\section{Agradecimentos}

Sem a grande atenção que as 30 empresas nos dispensaram, o suporte da FAPESP em termos de bolsa e o aporte de recursos do RECOPE/FINEP este projeto não poderia ter sido realizado. A estas instituições, nossos agradecimentos. Agradecemos também os 3 referees anônimos que muito contribuíram, com suas críticas e sugestões, para o aprimoramento do texto originalmente submetido.

\section{Referências Bibliográficas}

ASSOCIAÇÃO BRASILEIRA DE FUNDIÇÃO (ABIFA). A indústria de fundição no Brasil. Disponível em: http://www.abifa.org.br>. Acesso em: set. 1999.

BRYMAN, A. Research methods and organization studies. London: Uniwin Hyman, 1989.

CAMPOS, F. M. P.; DAVIES, G. J. Solidificação e fundição de metais e suas ligas. São Paulo: Editora da Universidade de São Paulo, 1978. p. 129-154.

COURTOIS, B.; KARAM, J. M.; LUBASZEWSKI, M.; SZEKELY, V.; RENCZ, M.; HOFMANN, K.; GLESNER, M. CAD tools and foundries to boost microsystems development. Materials Science \& Engineering B [Solid-State Materials for Advanced Technology], v. B51, Iss: 1-3, p. 242-253, fev. 1998.
DRAKE, K.; ABADIR, M.; STARK, S.; RHYNE, T.; ESKEW, M.; LOCKWOOD, L.; SALSBURG, K.; HARR, R.; CONCHA, L. Application specific electronic modules (ASEM) CAD/CAE/CAM interface specification alliance. Proceedings... IEEE Multi-Chip Module Conference MCMC, 1994. p. 44-49.

FERNANDES, F. C.; MULATO, J. C. The computarization level of industries in the city of São Carlos. In: Management and control of production and logistics, Oxford (UK): Pergamon Press/Elsevier Science Ltd., 1998. p. 595-600.

HENSHELL, R. D. IT in foundries - engineering data management and layout optimisation. Foundryman, v. 89, n. 2, p. 47-50, feb. 1996. 
ISERMANN, R.; MAIWALD, D.; NOLTE, K. Modern automation systems for metallurgy and industrial heating. Metallurgical Plant and Technology International, v. 20, n. 2, p. 6, apr. 1997.

LUTHER, N. B. How to achieve balanced production in your foundry. Modern Casting, v. 85 , n. 10 , p. 40-42, oct. 1995.

MILLS, J. Emerging trends in manufacturing systems. Foundry Management \& Technology, v. 125, n. 11, p. 22-24, nov. 1997.

PROPHET, A. M. New rules, new markets, new skills: ASICS in the 90s. Proceedings... Third Annual IEEE ASIC Seminar and Exhibit, 1990. p. T/3.1-2.

RANSING, R. S.; SRINIVASAN, M. N.; LEWIS, R. W. ICADA: intelligent computer aided defect analysis for castings. Journal of Intelligent Manufacturing, v. 6, Iss: 1, p. 29-40, feb. 1995.
SAN MARTIN, P.; CAMPANILI, M. Empresários condenam cancelamento de projeto de reciclagem de areia. $O$ Estado de S. Paulo, São Paulo, 5 de junho de 2002. Disponível em: http://www. estadao.com.br>. Acesso em: out. 2002.

SIPPER, D.; BULFIN, R. Production: planning, control, and integration. New York: McGrawHill, 1997.

ULUSOY, G.; OR, I.; SOYDAN, N. Design and implementation of a maintenance planning and control system. International Journal of Production Economics, v. 24, Iss: 3, p. 263-272, mar. 1992.

VERGARA, S. C. Projetos e relatórios de pesquisa em administração. 3. ed. São Paulo: Atlas, 2000.

ZACCARELLI, S. B. Administração estratégica da produção. São Paulo: Atlas, 1990.

\title{
INDUSTRIAL AUTOMATION AND COMPUTERIZED PRODUCTION MANAGEMENT SYSTEMS IN MAKE-TO-ORDER FOUNDRIES
}

\begin{abstract}
Foundry is a manufacturing process with a growing importance. The main objective of this paper is to analyze, in terms of automation and of computerized production management systems (CPMS), the make-to-order foundry in the interior of the state of São Paulo belonging to 5 main foundry industrial districts (Piracicaba, Indaiatuba, Limeira, São Carlos and Itu) with 10 to 250 workers. From the 61 enterprises in the interior of São Paulo State, 35 are situated in these 5 industrial districts (or in their neighborhood); we interviewed personally the industrial executive officer and visited the shop-floor of 30 among this 35 foundries. We have analyzed almost 200 frequency and contingency tables and draw several conclusions, for example: (i) among the three main problems and necessities related with production, two of them are directly related with automation and CPMS; (ii) automation and CPMS generate coincident interests on the make-to-order foundries.
\end{abstract}

Key words: foundry, make-to-order, automation, computerized production management systems. 